\title{
Experimental determination of demand side management potential of wet appliances in the Netherlands
}

\author{
M.R. Staats ${ }^{\mathrm{a}, \mathrm{b}}$, P.D.M. de Boer-Meulman ${ }^{\mathrm{b}}$, W.G.J.H.M. van Sark ${ }^{\mathrm{a}, *}$ \\ a Utrecht University, Copernicus Institute of Sustainable Development, Heidelberglaan 2, 3584 CS Utrecht, The Netherlands \\ ${ }^{\mathrm{b}}$ DNV GL, New Energy Technologies, Utrechtseweg 310, 6812 AR Arnhem, The Netherlands
}

\section{H I G H L I G H T S}

- Experimental determination of residential peak shift potential of wet appliances.

- Shifting demand results in peak reduction of $10 \%$.

- Photovoltaic self consumption accounts for $6 \%$ demand reduction.

\section{A R T I C L E I N F O}

\section{Article history:}

Received 7 August 2016

Received in revised form

17 December 2016

Accepted 18 December 2016

Available online 26 December 2016

\section{Keywords:}

Demand side management

Wet appliances

Photovoltaic systems

Peak shifting

Self-consumption

\begin{abstract}
A B S T R A C T
The potential of demand side management (DSM) of wet appliances (washing machine, dishwasher and tumble dryer) in households with photovoltaic (PV) systems is studied experimentally focusing on evening peak demand reduction and increase in PV self-consumption. In a sample of 100 Dutch households the electricity demand is monitored for one year at high time resolution. It is found that the dishwasher has the best DSM potential, with a median average peak reduction potential up to 35 $\mathrm{W}$ per household on average for all appliances, while PV self-consumption for the median household can be increased with $68 \mathrm{kWh} /$ year per appliance. The tumble dryer and washing machine's potentials are $30 \mathrm{~W}$ and $25 \mathrm{~W}$ per household, respectively, for the mean average peak reduction, and $38 \mathrm{kWh}$ and 28 $\mathrm{kWh}$, respectively, per household per year for increase in PV self-consumption per appliance. Further, the median peak reduction potential of a single group of wet appliances ranges from $1 \%$ to $5 \%$ of the power demand in peak hours, while combined they could add up to $10 \%$ of the total peak. The median increase in PV self-consumption is in the range between $1.5 \%$ and $4 \%$ for separate appliances, while the median total could provide an increase up to $129 \mathrm{kWh}$ per household per year if a household possesses and utilizes the potential of all appliances, which is about $6 \%$ of the annual household demand. In conclusion, DSM potential for wet appliances is limited.
\end{abstract}

(C) 2016 Elsevier Ltd. All rights reserved.

\section{Introduction}

\subsection{Renewables in the electricity grid}

The deployment of photovoltaic (PV) solar energy in the past decades has led to an impressive $227 \mathrm{GWp}$ installed capacity worldwide at the end of 2015 [1], covering $1.3 \%$ of the world's annual electricity demand. This growth is expected and targeted to grow to values surpassing the terawatt level. In the Netherlands, PV systems are predominantly installed in residential areas on the

\footnotetext{
* Corresponding author.

E-mail address: W.G.J.H.M.vanSark@uu.nl (W.G.J.H.M. van Sark).
}

roofs of privately owned homes. This will lead to a shift in the electricity supply chain from centralized high-power fossil fueled power plants to a decentralized bidirectional power flow electricity system. The inherent intermittent power generated by PV due to day-night and seasonal sequences, and cloud effects poses a challenge, as demand from households with PV is not following the generated PV power. This mismatch in production of solar energy and electricity demand is a grave concern of distribution system operators (DSOs) and utilities, since electricity demand and supply have to be balanced at all times.

These problems could be addressed on the one hand by shifting the load of appliances to other times of the day in order to reduce peak power demand and on the other hand by optimizing PV selfconsumption, i.e. by using the generated solar power directly in the household. The latter objective is not only attractive for grid 
operators and utilities, but also for the end users, especially in situations where net metering is not in force. This could be organized using smart energy management systems, usually referred to as smart grids. A smart grid can be defined as 'a set of software and hardware tools capable of routing power more efficiently, thus reducing the need for excess capacity' [2]. This effectively means that a smart grid is a local grid connecting several households, which will attempt to most efficiently match supply and demand by utilizing energy storage facilities such as electric vehicles and shifting demand load to a time where there is excess energy supply from for example solar panels. Smart grids may be quite complex because of these abilities and a lot of research is being conducted into the potential of smart grids to incorporate different energy sources, storage systems and users in relation to demand side management (DSM) and user acceptance [3-22].

\subsection{Demand side management}

A smart grid should be able to employ demand side management. DSM refers to the ability of consumers, manually and/or automatically, to respond to a signal by adjusting electricity demand to facilitate a better matching of supply and demand $[8,19]$. This signal can be a price signal, e.g., a dynamic electricity price, or a power mismatch signal, e.g., excess PV supply. A number of studies exist that specifically focus on DSM in residential areas. For example, various authors have reported on the development of algorithms to calculate the potential of demand side management $[13,20]$. Others have studied the potential of households to shift their behavior $[14,23,24]$. More recent studies have focused on investigating the shifting potential in real-life settings by providing households with smart appliances and studying their actual behavior [15,18,25]. Muratori et al. [21] found that the specific design of dynamic price programmes has significant effect on the potential for peak shifting of households. Also, government policies in the UK have been successful to improve DSM in the industry and residential sector [26].

On the household level, a theoretical study of a household integrated into a system with large renewable penetration in Turkey showed that a yearly reduction in cost of electricity of $3 \%$ would be possible if DSM was applied [27]. In a set of single family buildings in Sweden with 3-9 kWp PV system per building it was shown that up to $200 \mathrm{kWh}$ increase in self-consumption would be possible annually with DSM [28].

In a top-down research into the DSM potential of various European countries, it was found that the Netherlands would be able to change $4.36 \%$ of their energy demand with a slight effort, while a total of $12.68 \%$ of the demand could be changed with a large effort [29].

\subsection{Appliances suitable for demand side management}

Clearly, not all household electricity demand can be easily adjusted, as power demand for appliances such as TV-sets and computers is often bound to specific times of use, impeding the possibilities for DSM. Other appliances do not provide enough power demand or energy use to add up to a significant DSM potential, such as printers and radios [30]. Appliances that are used to cool products (cold appliances: freezers and refrigerators), often display relative high energy demand highly dispersed over the day [31], but DSM potential of cold appliances may be limited due to cooling demands.

A group of appliances that may show a high DSM potential are the wet appliances (washing machine, tumble dryer, dishwasher). With their share of electricity use of $17 \%$, they come second in electricity use as consumer electronics represent $22 \%$ [31,32]. These appliances embody both high energy use as well as high power demands, and allow for adjusting time of use. In an ideal case, inhabitants would fill these appliances and the smart grid software would interact with these appliances to control the time at which they have to start their operation. A case study in Belgium with a large sample of households showed that demand reduction using wet appliances is not only dependent on their electricity demand but also on the willingness of households to actively apply demand response [32]. The study concludes that demand reduction potential is about $21 \mathrm{~W}$ per household on average per year. A study using automated approaches showed relatively high DSM potential [25], while another simulation study showed only limited DSM potential [33]. Although automated approaches are expected to be more and more used in future, the present paper focuses on the potential of manual rescheduling of cycles using actual measured data instead of simulations and will try to identify what the energetic benefits are from such a scenario. Manual rescheduling will not require high investments and households have more influence on the rescheduling, which is likely to result in easier introduction of DSM in households, however dependent on willingness to adapt behavior [32]. Note that in the area that is used in this research, no smart appliances were installed.

This research will focus on the DSM potential of wet appliances in the sub-urban district Nieuwland in the city of Amersfoort in the Netherlands. This district is home to 500 small $(0.8-4.4 \mathrm{kWp})$ PV systems installed in 1999-2001 totaling 1.3 MWp [34]. One hundred households participate in a demand measurement scheme in which up to 5 appliances per household are monitored at 10 -s time resolution. Availability of such a detailed unique dataset is a prerequisite for a proper experimental analysis. This study contributes to a better understanding of the energetic role of wet appliances in current households, as well as their potential for load shifting and photovoltaic self-consumption.

This paper is further organized as follows. Section 2 provides background on PV, DSM, and demand profiles of wet appliances and Dutch household demand profiles. Section 3 details the methodology used. Analysis of results is presented in Section 4, and these are discussed in Section 5. Section 6 closes the paper with conclusions.

\section{Background}

\subsection{PV and DSM}

DSM can have multiple benefits for multiple actors in the electricity system. For the Distribution System Operator (DSO) the benefits would lie in the ability of dynamically changing demand to prevent congestion and (too) large peaks in the power flowing through the network cables. While in the last decades the peak moments were mainly during evening hours due to increased demand, large-scale incorporation of PV systems into the electricity grid leads to a peak moments around midday. For a residential district with a large amount of PV systems, a sunny spring or summer day could thus result in higher negative power flow than the positive power flow on a dark winter evening, resulting in higher demands of the electricity grid, which may lead to required investments in grid extension. By curtailing PV systems, grid investment can be reduced albeit with a negative consequence for PV owners in that their economic benefits will be lower. At the end of the afternoon, the reduction in PV power coincides with an increase in household consumption. Thus, high ramp rates need to be dealt with. DSM can be a solution by reducing peak demand, thereby decreasing the ramp rate. Pöyry delineated the usefulness of DSM for grid operators along a total of five dimensions [35]. These dimensions as well as the application of these dimensions to wet appliances are given in Table 1 . It was reported that $5 \%-15 \%$ reduction in peak demand 
Table 1

Dimensions of usefulness of DSM and application on wet appliances (based on [35]).

\begin{tabular}{|c|c|c|}
\hline Dimension & Explanation & Application of wet appliances \\
\hline Magnitude & How much power can be displaced? & About $2 \mathrm{~kW}$ per appliance (peak) \\
\hline Duration & How long can this power be displaced? & Depending on the appliance, between $15 \mathrm{~min}$ and $2 \mathrm{~h}$ \\
\hline Timing & At what time can this power be shifted and with what frequency? & $\begin{array}{l}\text { Through the whole day and evening, but it depends on how many } \\
\text { appliances are turned on at a certain time. The frequency is usually } \\
\text { multiple times a week. }\end{array}$ \\
\hline Notice period & $\begin{array}{l}\text { How far in advance does there have to be notice given of DSM } \\
\text { requirements? }\end{array}$ & $\begin{array}{l}\text { Should be at least some hours in advance, so homeowners can take into } \\
\text { account that they should fill the appliance. }\end{array}$ \\
\hline Location & At what level of the network is the DSM displaced? & At the distributed grid, connecting individual households. \\
\hline
\end{tabular}

at peak hours is possible [36], also implying that a large share of total electricity use in these hours cannot be shifted in time. One recent study has described barriers for DSM introduction for various stakeholders, which can also be country specific. For the Netherlands, price-based demand response and direct load control have been identified as most suitable, while they may not be beneficial for market players or DSOs. Optimizing DSM such that all stakeholders wil benefit will be complex, and aggregator companies have been suggested that would manage energy and administrative flows [33,37].

Regarding PV feed in, net metering is current practice in the Netherlands. Hence, there is no financial incentive to increase PV self-consumption, as all electricity delivered to the grid can be used at another time without any additional costs. However, the government has stated that in the near future net metering in its present form will be abolished, but not before 2020 [38]. As tax constitutes two-thirds of the total current electricity price, a relatively large financial incentive is created to increase PV selfconsumption if net metering is abolished.

Wet appliances seem to have a good potential for DSM to increase PV self-consumption. In the Netherlands penetration of wet appliances is high at $94 \%, 58 \%$, and $54 \%$, for washing machines, tumble dryers, and dishwashers, respectively [39]. Shifting demand from the evening to the afternoon will increase PV selfconsumption. For a realistic analysis of PV self-consumption it is essential to measure actual power demand using small time steps, to be able to balance power flows for every moment of the appliance cycle.

\subsection{Power profiles}

The demand profile of a wet appliance depends on the technological characteristics of the appliance, brand, type, and specific program selected. However, generic patterns for each type of appliance have been presented at 15-min time resolution, as shown in Fig. 1 [40].

\subsubsection{Washing machine}

The first part of the washing machine cycle consists of pumping of water through the detergent container into the drum (Fig. 1(a), time step 1), which requires relative low power demand for a short time. The further cycle can be subdivided in three main steps. First the water is heated in the drum (time step 2 and 3 ), which requires the bulk share of the total energy requirement. The drum rotates to evenly divide the heat through the water in the drum. Heating stops after reaching the set point temperature. Then the drum continues to rotate to stir the clothes (time step 4 and 5), requiring a much lower power demand. In the next step, water is pumped out, which is combined with slow centrifuging of the clothes. After all water has been pumped out, centrifuging the clothing is started using a substantial higher amount of revolutions per minute compared to the previous step, and power demand increases somewhat (step 6). Finally, the water pump and other accessories (console, lighting) require a negligible amount of power (compared to the rest of the cycle). This generic pattern requires $0.89 \mathrm{kWh}$ per cycle.
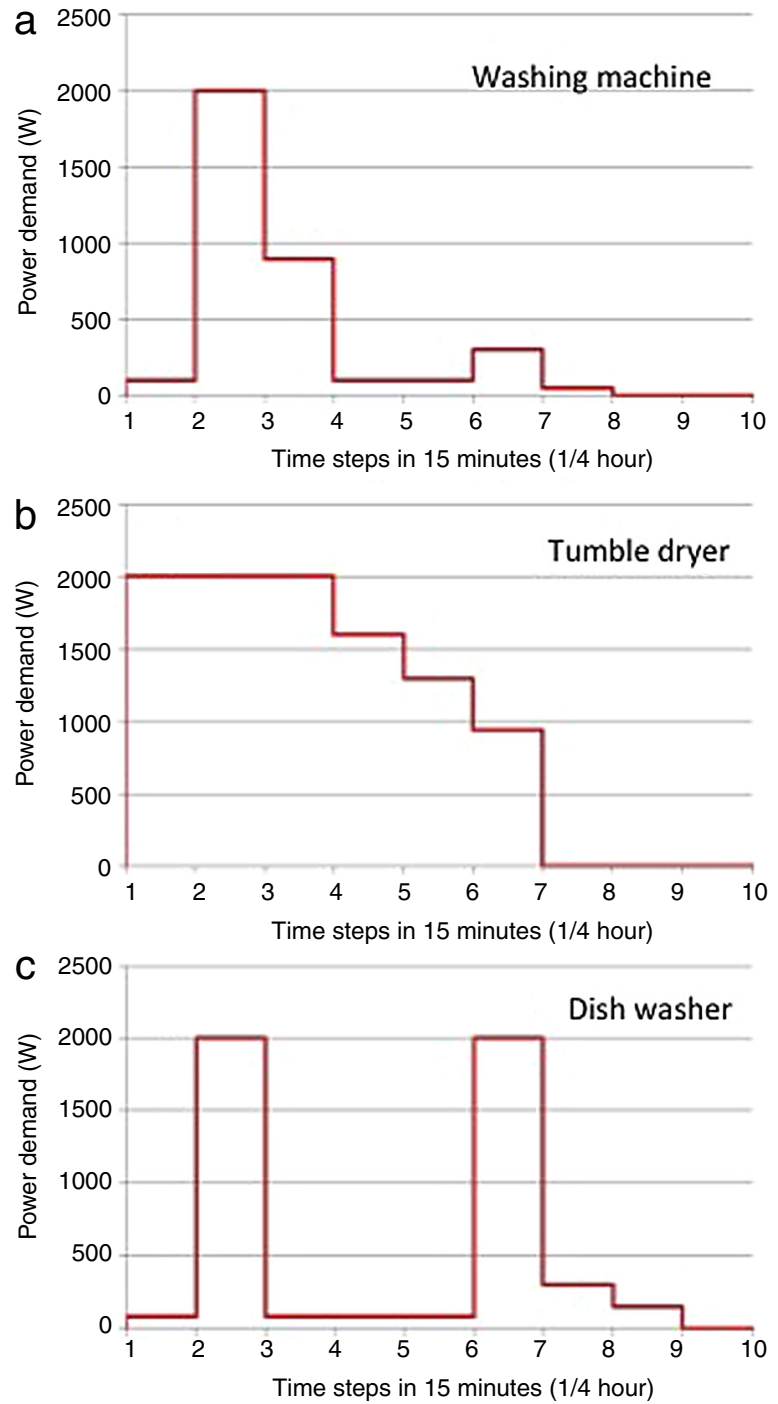

Fig. 1. Power demand profiles for (a) washing machines, (b) tumble dryers, and (c) dish washers (after [40]).

\subsubsection{Tumble dryer}

A significant amount of households that have a washing machine also possess a tumble dryer. Nevertheless, a weak correlation exists between washing cycles and tumble dryer cycles. A generic cycle of the tumble dryer (Fig. 1(b)) entails moist clothes from the washing machine to be put into the tumble dryer. Air is sucked into the machine from the surroundings of the tumble dryer and is heated using a heating resistance. The water in the clothes evaporates and leaves the drum with the cooled-down air. Initially there is a high power demand in the cycle for the resistance and the wet clothes to heat up. As the water reaches its evaporation temperature, the power demand is lowered as a part of the airflow 

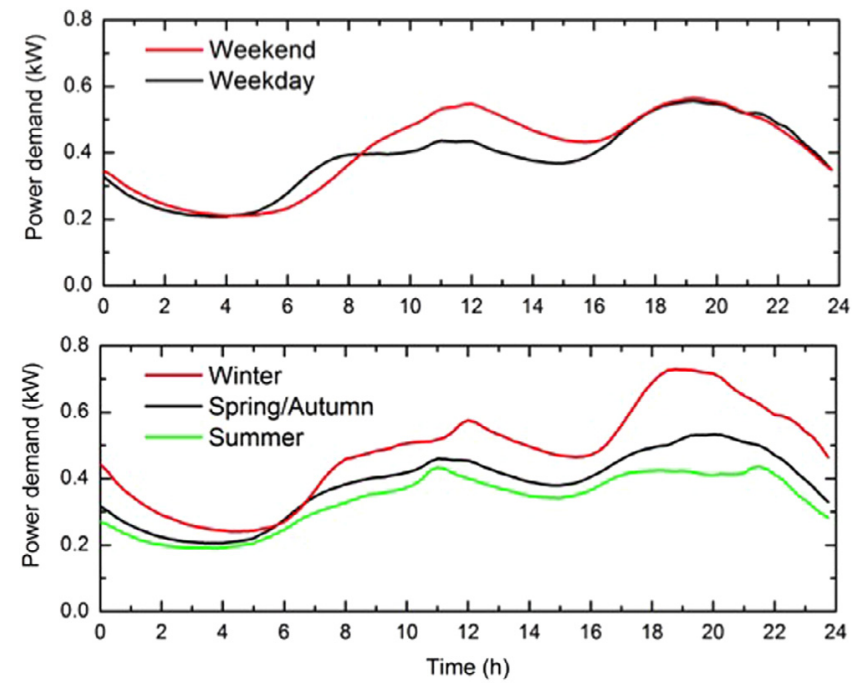

Fig. 2. (a) Demand profiles for workdays and weekends for Dutch households; (b) Demand profiles for three seasons for Dutch households. Based on 15 min interval Synthetic Load Profiles from Nederlands EnergieData Uitwisseling (Dutch Energy Data Exchange) [43]

is used to transport evaporated water out of the drum. The general profile of the tumble dryer thus shows a high $(\sim 2 \mathrm{~kW})$ power demand in the beginning (time steps 1-3), after which it reduces to a lower $(\sim 1 \mathrm{~kW})$ demand. The generic pattern requires $2.46 \mathrm{kWh}$ per cycle.

\subsubsection{Dishwasher}

The dishwasher starts with an initial rinse. This requires some pumping and rotation of a spraying arm (Fig. 1(c), step 1). Then, the water is heated to the appropriate temperature and sprayed through the rotating spraying arm onto the dishes, requiring a high power demand (step 2). The water is used to keep rinsing for several rinsing cycles. For the last rinsing cycle (step 6), the water is heated up again to make the dishes dry faster. After the last rinsing cycle, the water is pumped out and electronics require a small amount of electricity. The generic pattern requires $1.19 \mathrm{kWh}$ per cycle.

\subsection{Household electricity usage}

Dutch households consume about $20 \%$ of the total electricity demand in the Netherlands, which equates to $3050 \mathrm{kWh}$ per household on average [41] (end 2014). A household's specific electricity demand depends on a large amount of variables, such as the size of the house, energy efficiency of appliances and the amount of inhabitants. Other electricity consumption inducing variables are behavioral: the presence profile of inhabitants in the house and the activities related to electricity use.

Power demand fluctuates depending on the type and amount of appliances used on a specific time by inhabitants. A commonly used differentiation for electricity use through the week is between working days (Monday through Friday) and weekend days (Saturday and Sunday) [30,42]. As typically inhabitants are absent from home during working hours on workdays, there is less power demand in these hours compared to the weekends. The power demand between about 9:00 and 17:00 in the weekend is considerably higher than on working days. These differences are clearly visible in a load profile for an annual average of all working days and an average of all weekends (Fig. 2(a)) [43].

Finally, seasonal differences are also observed, due to differences in ambient temperature, hours of sunlight and behavioral differences between seasons. We identify three major seasonal patterns following [28], i.e., summer, winter, and spring/autumn, with low power demand in summer, high demand in winter and average demand in spring/autumn. In this paper we assume that demand in spring and autumn are similar. The seasonal differences are also distinctly visible from the demand profiles, see Fig. 2(b).

\section{Methodology}

\subsection{Dataset}

The dataset used in this research consists of raw data obtained from the pilot project Smart Grids: Rendement voor iedereen. ${ }^{1}$ This pilot project encompassed the installation of electricity meters in 180 houses in Utrecht (district Lombok), and Amersfoort (district Nieuwland). For the present research, only data taken in Amersfoort are used. The district was built in the 1990s and can be characterized as a suburban district with on average 2.7 inhabitants per household: half of the households are families with children, while the other half consists of an equal amount of two- and one-person households [44]. The houses within the dataset are large terrace houses of which most were built with solar panels included, leading to a very large solar panel penetration rate of 90\% [34].

In these houses the household net electricity demand (or surplus in case of high solar power production), solar power production and demand of several large electric appliances (refrigerators, freezers, washing and dishwashing machines or tumble dryers) have been measured from 1 July 2013 for over a year. A total of almost 1000 power demand meters (plugs) were installed during the first few months of the project to measure power consumption at 10-s interval. These plugs had a unique ID, and homeowners had to identify the appliances to these IDs themselves. Energy consumption was measured on a 15-min interval. Measurement equipment was provided by Net2Grid $\mathrm{BV}^{2}$ and uses Internet connection to send acquired data to a central server database.

\subsection{Data analysis}

The data handling and analysis was performed as follows: after data management and selection, first individual cycle analysis was performed, followed by combining that for all households. The final dataset was used to investigate effects on peak demand and self-consumption by employing the general purpose programming language Python.

\subsubsection{Data selection}

As the dataset is constructed by cooperation of researchers and homeowners, not all data is utilizable due to technical problems in the implementation of the equipment. Other parts of the data are not utilizable due to implementation faults, such as not or incorrectly linking the plugs (IDs) to a certain category in the database. This is likely to happen when plugs are switched between appliances without updating the online database. Therefore, the database had to be cleaned to exclude non-utilizable data. The following criteria were used:

- Omit IDs with large high-low demand spikes (unrealistic ramp rate).

- Omit IDs which do not display any usage or production over several weeks.

\footnotetext{
1 The project Smart Grids: Rendement voor Iedereen ("Smart Grids: Benefit for all") was initiated by the Utrecht Sustainability Institute, the Universities of Utrecht and Groningen, semi-public bodies as DSO Stedin and Economic Board Utrecht and several companies (DNV GL, Capgemini, Ecofys, Lomboxnet), see http://www.smartgridrendement.nl.

2 https://www.net2grid.com.
} 
- Omit IDs which use (very) unlikely outputs, such as very high power demand ( $>10 \mathrm{~kW})$.

- Omit IDs which are not categorized as household, solar panel or wet appliance.

Subsequently, the remaining IDs were manually reviewed by analyzing the demand profile and checking whether that was consistent with the provided category. The following guidelines were used for this process:

- Households: There should always be some demand (or at least for the largest part of the day), demand peak cannot exceed $6 \mathrm{~kW}$ multiple times a week, and in general lower demand at night compared to the rest of the day.

- Solar panels: There should be power production, identified as negative power demand, power production should peak around noon and be zero at night. Power production should generally be higher in summer than winter.

- Wet appliances: Demand cycles of around one or two hours, obvious cycles of power demand where most of the time demand is around zero except during a cycle, cycles are (usually) done at least once a week. Profile should resemble a profile as expected from that specific appliance (Fig. 1).

Due to data availability, this research will be limited to an analysis of three seasons: winter, spring and summer. As autumn demand is similar to spring demand, this was not considered as a shortcoming. For every season a period of four weeks is selected based on the following criteria:

- The period of four weeks of a specific season should be at least two weeks from the meteorological boundaries

- The period should be chosen in such a way that the amount of measurement gaps is minimized.

\subsubsection{Individual cycle analysis}

Each individual cycle of each wet appliance was analyzed using an iterative process. The general patterns (Fig. 1) showed that the bulk of energy use and power consumption was within the $2000 \mathrm{~W}$ peaks of each cycle, hereafter denoted as 'bulk moments'. For individual cycle analyses all cycles are reduced to one or two bulk moments. For every individual appliance for each cycle we thus found: (a) length of bulk moments, $L_{w}$; (b) average power demand of bulk moments, $P_{w_{-} a v g}$; (c) day of the week and time of the day; (d) amount of cycles per day.

Washing machine

The bulk moment of washing machines is clearly in the beginning of the cycle. The minimal power of all the individual cycles of all washing machines was found to be at least $1500 \mathrm{~W}$. The bulk moment variables were calculated by iterating a sequence over each time step as shown in Table A.1 (see Appendix), for every day. This has resulted in the start time and date for both the beginning and end of the bulk moment, as well as in the average power $P_{w_{\_} a v g}$ and length $L_{w}$ of the bulk moment. The end result of the process is shown in Fig. 3(a).

Tumble dryer

The bulk moment of the tumble dryer is for electric resistance tumble dryers divided in multiple drying stages (see Fig. 1(b)). To acknowledge this difference, two main bulk moments have been identified in each cycle. The first bulk moment being the start of the cycle, the second bulk moment as being connected to the first directly, but with a considerably lower power demand. Manual verification of tumble dryer cycles showed a minimum power of the first bulk moment of $1800 \mathrm{~W}$ and a minimum of the second bulk moment of $700 \mathrm{~W}$. These numbers where used in the tumble dyer iteration sequence as shown in Table A.2 (see Appendix). Fig. 3(b) shows an example of an electric resistance tumble dryer analysis. Note that other types of tumble dryers follow a different
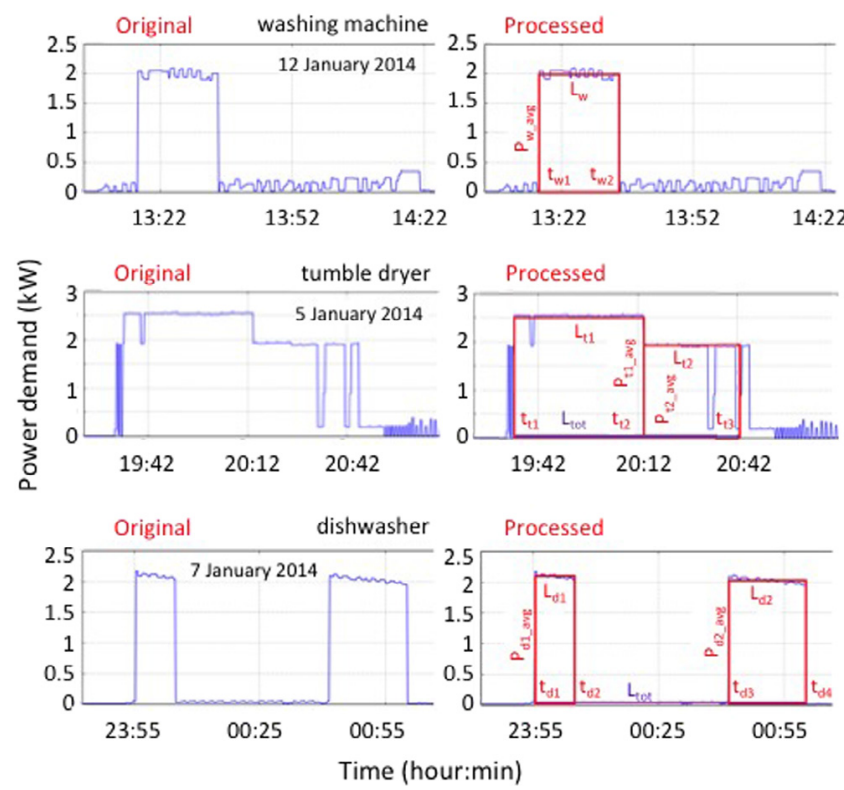

Fig. 3. Graphical representation of bulk moment iteration outcomes for (top) washing machine cycles: in this example $P_{w \_a v g}=1990 \mathrm{~W}$ and $L_{w}$ is $17 \mathrm{~min}$ and $30 \mathrm{~s}$, with total energy of $0.58 \mathrm{kWh}$; (middle) an electric resistance tumble dryer cycle: in this example $P_{t 1 \_a v g}=2500 \mathrm{~W}, L_{t 1}=38 \mathrm{~min}, P_{t 2 \_a v g}=1940 \mathrm{~W}$, $L_{t 2}=29 \mathrm{~min}$, with total energy of $2.52 \mathrm{kWh}$; (bottom) a dishwasher cycle: in this example $P_{d 1 \_a v g}=2120 \mathrm{~W}, L_{d 1}=9 \mathrm{~min}, P_{d 2 \_a v g}=2020 \mathrm{~W}, L_{d 2}=20 \mathrm{~min}$, with total energy $0.99 \mathrm{kWh}$.

demand profile. For example, heat pump tumble dryers use very different technology, and their demand profiles are similar to those of washing machines. Thus, for heat pump tumble dryers, the washing machine iteration sequence is selected, with a minimum power of $400 \mathrm{~W}$ instead of the $1500 \mathrm{~W}$ washing machine level.

\section{Dishwasher}

As is shown in Fig. 1(c), the bulk moments in dishwasher cycles are not connected to each other but spread over the cycle. Thus, for each cycle two separate bulk moments are identified. The minimum amount of power demand for dishwashers was identified to be $1000 \mathrm{~W}$. The iteration sequence used to calculate the cycle variables is shown in Table A.3 (see Appendix). Fig. 3(c) shows an example analysis. Some dishwashers do not have more than two $2000 \mathrm{~W}$ peaks during one cycle. To cope with this, the iteration sequence is adapted (Table A.4) to continue to iterate and add up the peaks until the dishwasher is off.

\subsubsection{Combined cycle analysis}

The aim of the combined cycle analysis is to determine to what extent appliances are used simultaneously at households, thus resulting in an addition of power demand in the district. Power demand is summed as follows:

for each time step $t: P_{\text {app_total }}(t)=\sum_{i=1}^{N}\left[P_{i}(t)\right]$

where $P_{\text {app_total }}(t)$ is the total power demand of all appliances at time $t$ and $P_{i}(t)$ is the power demand of appliance $i$ at time $t . N$ is the total amount of appliances in the appliance group. $P_{\text {app_total }}$ is calculated for all three appliance groups.

A load duration curve is constructed to investigate how power demand varies over time. It shows a descending time series where total power demand of all appliances is sorted from high to low demand. From a load duration curve the total time for which the power is above or below a certain threshold can be obtained. Also, it can be derived what the maximum peak load of the appliances is and how long high power demands are occurring in the selected 
time range. It can be expected that for the majority of time, power demand of the appliances is zero, and high peaks are not likely to occur for very long periods of time. Thus, a steep curve at short times is expected, and a more gradual slope at longer times.

To find the share of each type of appliance use in total electricity use, for each seasonal period, total energy use of all appliances is compared to total electricity use of all households. The total demand profile of all households is calculated by:

for each time step $t: P_{\text {hh_total }}(t)=\sum_{i=1}^{H}\left[P_{h h_{-} i}(t)\right]$

where $P_{\text {hh_total }}$ is the total net power demand of households and $P_{\text {hh_total }}$ is the power demand of household $i . H$ is the total amount of households. To correct for solar electricity and obtain the gross instead of the net power profile, the same is done for the solar panels, where $P_{h h \_} i$ is substituted for solar panel individual profile $P_{\text {solar } i}$, which will obtain the total production profile of all solar panels $P_{\text {solar_total }}$.

The gross demand profile of all households is then calculated using the following formula (note that $P_{\text {solar_total }}$ is a negative number, by definition):

for each time step $t$ :

$P_{\text {hh_total_gross }}(t)=P_{\text {hh_total }}(t)-P_{\text {solar_total }}(t)$.

The total energy use of both households and appliances in a certain period is then calculated as:

for each time step $t: E_{\text {hh_total }}=\sum_{t=1}^{T}\left[\frac{P_{h h_{-} \text {total_gross }}(t) * \Delta t}{3600}\right]$

where $E_{\text {hh_total }}$ is the total electricity use of the households in the calculated period in Wh, $T$ is the total amount of time steps in the calculated period, $P_{h h_{-} \text {total_gross }}$ is the total gross power of all households on time $t$ and $\Delta t$ is the length of the time step in seconds. The same equation can be used if $P_{\text {hh_total gross }}$ is substituted for $P_{\text {app_total }}$, which will result in the total electricity use $E_{\text {app_total }}$ of the appliance in Wh.

The share of electricity use of the appliance group in the total electricity use of the household is then:

for each appliance : Share in electricity use $(\%)=\frac{E_{\text {app_total }}}{E_{\text {hh_total }}}$.

\subsubsection{Peak reduction analysis}

To calculate the reduction potential in peak hours, first the peak hours have to be identified. These are defined in this research as the three hours around the moment with highest power demand. To exclude very short power peaks of less than a minute during offpeak hours, the moment with highest power demand is defined as the highest five-minute interval average power demand throughout the day. This five-minute interval is referred to as the peak moment, while the period of three hours around this peak moment is referred to as the peak period. They are defined as follows:

$$
\begin{aligned}
& P_{\text {peak_moment }}(t) \\
& =\overline{\left\{P_{\text {hh_total }}(t)+P_{h h_{-} \text {total }}(t+1)+\cdots+P_{h h_{-} \text {total }}(t+5 \min )\right\}}(6) \\
& P_{\text {peak } \_ \text {moment }}=\max \left[P_{\text {peak_moment }}(t)\right] \\
& P_{\text {peak_period }}(t)=\left\{P_{\text {hh_total }}(-1.5 \mathrm{~h})+\cdots+P_{\text {peak_moment }}\right. \\
& \left.+\cdots+P_{\text {hh_total }}(+1.5 \mathrm{~h})\right\} \\
& P_{\text {peak_period }}=\overline{P_{\text {peak_period }}(t)} \text {. }
\end{aligned}
$$

Reduction potential of a wet appliance group is calculated by removing the power demand of all appliances from that group from the total power demand of all households in the peak period:

for each time step $t$ in $P_{\text {peak_period }}(t)$ :

$P_{\text {hh_reduced }}(t)=P_{\text {hh_total }}(t)-P_{\text {app_total }}(t)$

where $P_{\text {hh_reduced }}$ is the power demand stripped from the power demand of an appliance groups. $P_{\text {app_total }}$ is the total power demand for a certain appliance group (or a combination of appliance groups).

To obtain the impact on peak moment and peak period of excluding these appliances, $P_{\text {peak_moment }}$ and $P_{\text {peak_reduced }}$ are recalculated using $P_{h h_{-} \text {reduced }}$ instead of $P_{h h_{-} \text {total }}$. The total power reductions for both peak moment and peak period are then calculated as follow:

$$
\begin{aligned}
& \text { for each day }: P_{\text {moment_reduced }} \\
& \quad=P_{\text {peak_moment }}\left(P_{\text {hh_total }}\right)-P_{\text {peak_moment }}\left(P_{\text {hh_reduced }}\right) \\
& \text { for each day }: P_{\text {period_reduced }} \\
& \quad=P_{\text {peak_period }}\left(P_{h h \_t o t a l}\right)-P_{\text {peak_period }}\left(P_{h h \_r e d u c e d}\right)
\end{aligned}
$$

where $P_{\text {moment reduced }}$ is the reduction of the highest peak throughout the day due to the excluding of one or more appliance groups and $P_{\text {period_reduced }}$ is the reduction of the average power demand over the peak period due to the excluding of one or more appliance groups.

\subsubsection{PV self-consumption analysis}

The PV self-consumption potential is calculated by shifting the use of a certain appliance from a time with limited or no solar production to a moment with high solar power production. This is done per individual house, where it is identified which cycles are to be displaced and to which moment these cycles have to be moved. Households need a minimum amount of solar panels (at least $2 \mathrm{kWp}$ ) to have enough solar power production to have a significant potential of self-consumption for appliances that use about $2000 \mathrm{~W}$ in their peaks. To prevent a negative effect of a shortage of solar panels or a positive effect of very large amounts of solar panels (more than $4 \mathrm{kWp}$ ), all households power profiles are stripped from their house-bound solar panel power profiles, after which an average set of solar panels (based on actual solar panel power profiles in the dataset) of $3 \mathrm{kWp}$ is added to the households. The new power profile for an individual household is then:

for each time step $t$ :

$P_{h h \_n e w}(t)=P_{h h \_o l d}(t)-P_{h h \_s o l a r}(t)+P_{\text {avg_solar }}(t)$

where $P_{h h \_n e w}$ is the new household profile, $P_{h h \_o l d}$ is the household profile from the dataset, $P_{h h_{-} \text {solar }}$ is the power profile of solar panels from the household and $P_{\text {avg_solar }}$ is the average profile of a $3 \mathrm{kWp}$ solar panel system from the dataset.

From the $P_{h h_{n} \text { new }}$ the appliance cycles are shifted in time, which requires a displacing algorithm. For this algorithm the following conditions are applied:

- Washing machine cycles have to be displaced on the same day

- Dishwashers used before $5 \mathrm{pm}$ are displaced on the same day, while dishwashers used after $5 \mathrm{pm}$ are displaced to the day after

- Tumble dryers can only be displaced in combination with the washing machine, as their use is linked

- When multiple cycles are present on a day, only one cycle can be displaced. The cycle which has the highest $P_{\text {hh_new }}(t)$ at the moment of start is displaced. As all cycles of an appliance have the same peak power, the cycle with the highest $P_{\text {hh_new }}(t)$ at the moment of start is assumed to be the cycle which currently uses the lowest amount of solar power. 
Table 2

Average daily electricity consumption, PV production and relative consumption of three appliance types.

\begin{tabular}{|c|c|c|c|c|}
\hline Seasonal period & Winter & Spring & Summer & Unit \\
\hline Average household consumption & 13.06 & 11.13 & 9.71 & kWh/day \\
\hline Average PV production ${ }^{\mathrm{a}}$ & 1.74 & 7.98 & 8.86 & $\mathrm{kWh} /$ day \\
\hline Average washing machine consumption ${ }^{\mathrm{b}}$ & 4.79 & 4.98 & 4.73 & $\%$ \\
\hline Average tumble dryer consumption ${ }^{\mathrm{b}}$ & 7.84 & 7.71 & 6.54 & $\%$ \\
\hline Average dishwasher consumption ${ }^{\mathrm{b}}$ & 7.79 & 9.38 & 7.26 & $\%$ \\
\hline
\end{tabular}

${ }^{a}$ For all households with solar panels (production depends on amount of Wp installed).

b Average percentage for households which possess these appliances.

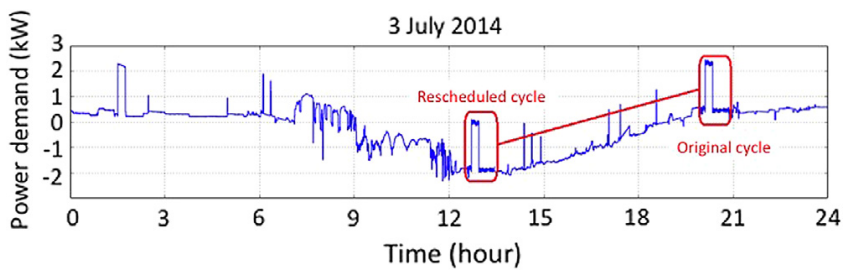

Fig. 4. Example of shifting the evening washing machine use to midday, when solar power matches demand.

\section{Washing machine}

The typical duration of a washing machine cycle is $1.25 \mathrm{~h}$. Therefore, a minimal difference between the start times of two cycles is taken to be $1.5 \mathrm{~h}$, allowing $15 \mathrm{~min}$ for unloading and reloading. Also, the peak of $2000 \mathrm{~W}$ is $15 \mathrm{~min}$ long, thus the algorithm is optimized to fit this 15 min peak moment to the 15 min period with the highest net power production. The algorithm is given in Table A.5 (Appendix) and is iterated over all households and all days in the three seasonal periods. An example of the resulting shift is shown in Fig. 4 where the washing machine cycle starting at $8 \mathrm{pm}$ is shifted to $1 \mathrm{pm}$, when solar power is at maximum.

Tumble dryer

The tumble dryer use is directly related to the use of the washing machine. Changing one of these appliances is likely to result in the necessity to also change the start time of the other appliance. Thus, a minimum start time of $11 \mathrm{pm}$ is used. The algorithm (Table A.6, Appendix) then becomes comparable to that of the washing machine, except for the minimal start time and the way in which the new start time is determined. The peak time of tumble dryers can range from 30 min to two hours, hence the new start time is the time where the net production over the length of the cycle is the highest. For a length of the cycle of $1 \mathrm{~h}$, the new start time is the start of the period with highest solar production for the next hour.

\section{Dishwasher}

The principle of the dishwashers' algorithm is the same as that used for the washing machine algorithm, with the exception that the exact start and end moments of the dishwasher cycle can easily be obtained. Thus, instead of using the standard $1.25 \mathrm{~h}$ for the dishwasher cycle displacement, the actual length of the cycle that is displaced will be used in this algorithm (Table A.7, Appendix).

\section{Results}

\subsection{Dataset}

The three seasonal periods identified of four weeks are all based on a total of 25 days where data was available. As a result of the data selection process, data from 53 of the 100 households have been selected for this work. For all three seasonal periods the average daily energy use has been calculated for the households, as well as PV production. This is shown in Table 2, as well as the average percentage of energy use by the three wet appliance types.
Table 3

Total, average, median, maximum and minimum amount of cycles for washing machines, tumble dryers, and dish washers per period of 25 days for all three seasonal periods. Total amount of washing machines, tumble dryers and dishwashers is 42,23 , and 24 , respectively.

\begin{tabular}{lllll}
\hline & & Winter & Spring & Summer \\
\hline Washing machines & Total cycles & 808 & 698 & 632 \\
& Average & 19.2 & 16.6 & 15 \\
& Median & 17 & 15 & 14 \\
& Maximum & 47 & 50 & 41 \\
Tumble dryers & Minimum & 2 & 2 & 0 \\
& Total cycles & 288 & 298 & 252 \\
& Average & 12.5 & 13.0 & 11.0 \\
& Median dryer & 11 & 13 & 7 \\
Dishwashers & Maximum & 41 & 44 & 26 \\
& Minimum & 2 & 2 & 1 \\
& Total cycles & 439.5 & 423 & 352 \\
& Average & 19.1 & 18.4 & 15.3 \\
& Median & 17 & 16 & 12 \\
& Maximum & 41 & 43 & 35 \\
& Minimum & 5 & 4 & 1 \\
\hline
\end{tabular}

\subsection{Individual cycle analysis}

The households within this study mainly consist of families with children, which is reflected in the number of cycles of all the wet appliances observed in the 25-day periods, see Table 3. Appliances are used on average every other day.

\subsubsection{Washing machine}

The results from Table 3 show there are great differences between the households in washing machine use, with maximum of over 40 cycles and minimum of 2 (even 0 ), in the four weeks, while seasonal differences are small. In the summer obviously less clothing is needed and the amount of cycles is lower.

The time of day when the cycle starts, shows when energy for the washing machine cycle is demanded and thus if that can be matched with solar power. The start time also indicates the possibility of reducing peak demand, as appliances started in peak hours could be turned off. The distribution of start times is shown in Fig. 5(a) for the three seasonal periods. A clear preference is apparent for using the washing machine in the morning and afternoon (between 08:00 and 17:00), while they are rarely used in the evening and night (between 17:00 and 08:00). There is only moderate difference between the uses in different seasonal periods. Between 08:00 and 17:00 almost 70\% of all washing cycles are started. Another difference in use of the washing machines can be found in the contrast of workdays to weekends (not shown). Overall energy use is typically higher in the weekends as the presence.

\subsubsection{Tumble dryer}

While tumble dryers are connected in use to the washing machines, there is no relative high winter peak similar to washing machines (Table 3). The combined use of all tumble dryers in the spring seasonal period even exceeds the use in the winter seasonal period, which is an unexpected result. Differences between 


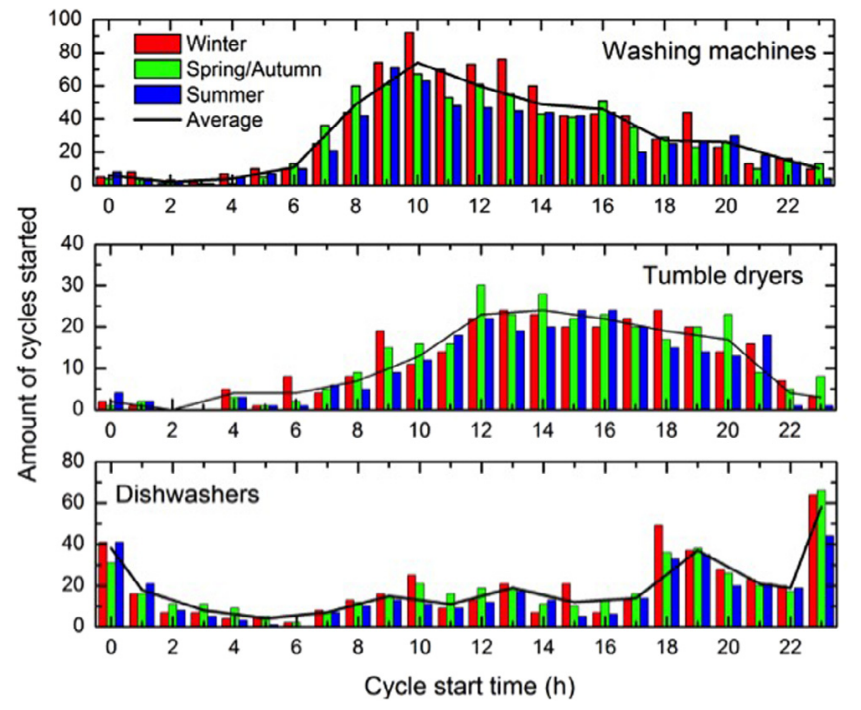

Fig. 5. Cycle start times of wet appliances for all three seasonal periods.

average cycles per dryer are rather small, indicating limited effects of the seasons on the use of tumble dryers. It is interesting to note that summer use is not that much different from winter and spring use.

The cycles are for all seasonal periods concentrated in the afternoon and early evening, as evidenced in Fig. 5(b). The tumble dryer use peaks are between 12:00 and 15:00. This is obviously linked to washing machine use. Even though there are differences between seasonal periods, for all periods the major share of the washing machines is used between 12:00 and 21:00, where for all seasons between $65 \%$ and $69 \%$ of all tumble dryer cycles are started within these $9 \mathrm{~h}$ of the day. The use of tumble dryers is on average much higher in the weekends than through the weekdays, especially in winter and spring.

\subsubsection{Dishwasher}

The average amount of cycles in a period of dishwashers is similar to those of washing machines, ranging from 19 in the winter to 15 in the summer (Table 3). As with washing machines, the maximum amount of cycles is not very different for the different seasonal periods.

The times of start of the dishwasher cycles differs substantially from those of the washing machine and tumble dryer, see Fig. 5(c). Two peaks are apparent, the first in the early evening and the second at night. As dinnertime in the Netherlands is between 17:00 and 19:00, some dishwashers are started immediately after dinner. Others start when inhabitants go to bed. In every seasonal period, between $60 \%$ and $68 \%$ of the cycles are started within the timeframe between $17: 00$ and $02: 00$, which is only $37.5 \%$ of the hours of the day. Only small deviations between the weekdays and weekend days are present.

\subsection{Combined cycle analysis}

The load duration curves are calculated are shown in Fig. 6. For the washing machines the peak load within the seasonal periods is around $14 \mathrm{~kW}$ in spring, $15.5 \mathrm{~kW}$ in summer, and $13 \mathrm{~kW}$ in winter. These peaks are equivalent to power demand of about 7 washing machines requiring maximum power at the same time, which is $17 \%$ of the total amount of washing machines. It is important to note that these peaks are only reached for a short moment (less than $100 \mathrm{~s}$ ) in the whole period. A combined load of higher than $10 \mathrm{~kW}$ was only observed between 8 min (spring) and $1.5 \mathrm{~h}$ (winter) duration, which is only a very small part of the whole
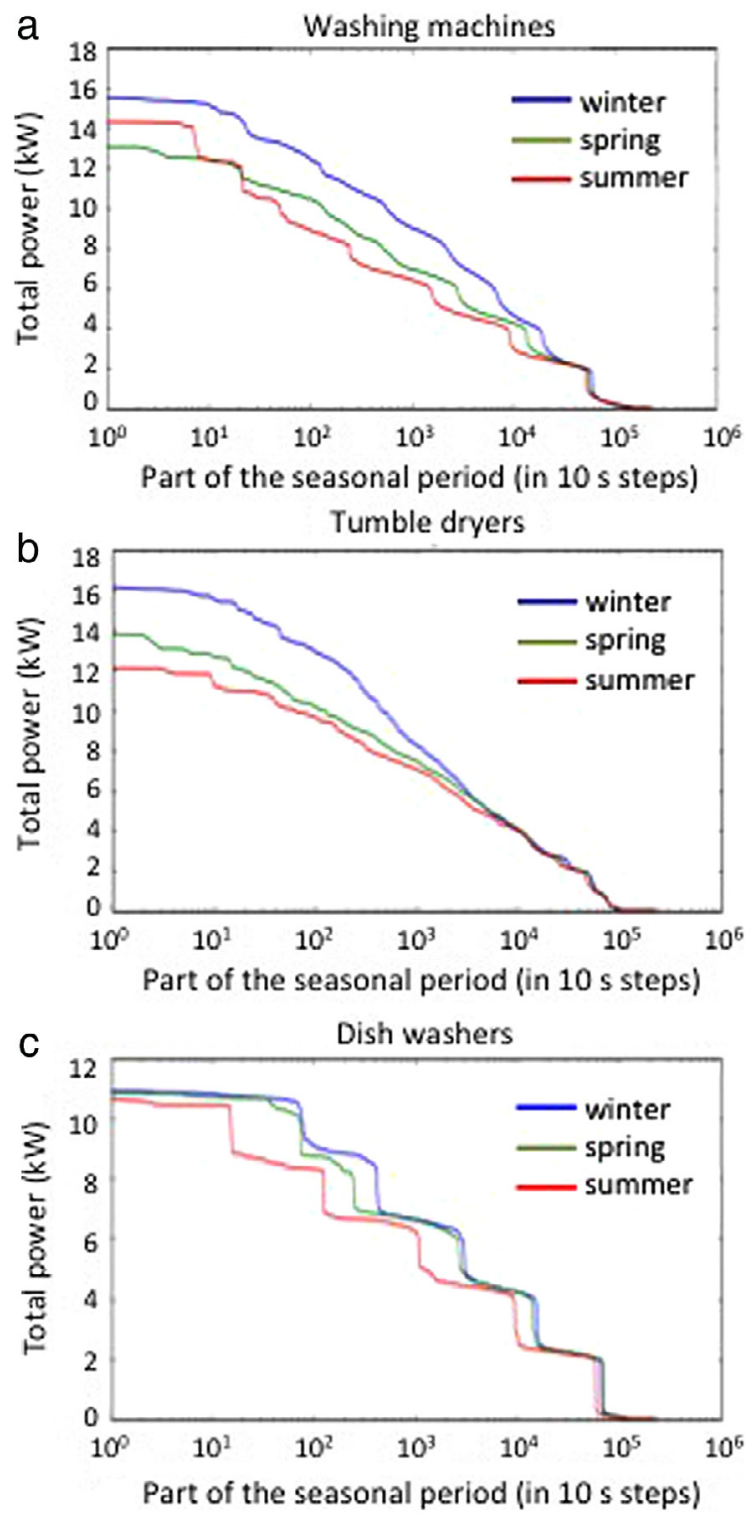

Fig. 6. Load duration (with logarithmic $x$-axis) curves for (a) 42 washing machines, (b) 23 tumble dryers, and (c) 24 dishwashers, for all seasonal periods.

seasonal period. A $10 \mathrm{~kW}$ combined load is about $20 \%$ of total power demand. Loads of more than $4 \mathrm{~kW}$ make up between 25 (summer) and 53 (winter) hours of the whole seasonal period, which is $4.1 \%$ and $10.6 \%$ of the whole seasonal period. This indicates that, on average, in the winter period every day the combined load of all washing machines requires $4 \mathrm{~kW}$ of power at some moment in the day.

The peaks of the combined load of the tumble dryers are very similar to those of the washing machines, with the summer peak being a bit lower $(12 \mathrm{~kW})$ and the winter peak a bit higher $(16 \mathrm{~kW})$. The duration that the combined load is above $10 \mathrm{~kW}$ is similar to that for the washing machine, i.e., between $11 \mathrm{~min}$ (summer) and $82 \mathrm{~min}$ (winter). The load above $4 \mathrm{~kW}$ is around $30 \mathrm{~h}$, which is $5 \%$ of the total amount of hours in the seasonal periods. While the amount of tumble dryers is only about half of the amount of washing machines, the combined peaks of these appliances are very similar. This result indicates that for a set of households, the 'stress' delivered on the grid is similar for washing machines and tumble dryers, even though the penetration rate of washing machines is much higher. However, the moment when this stress occurs is also important, where high combined load is 


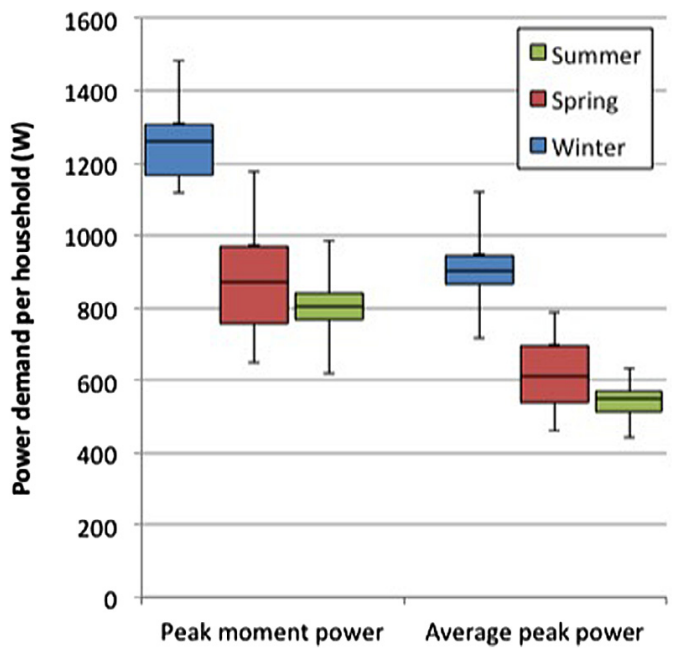

Fig. 7. Peak moment power and peak average power for all three seasonal periods on average per household.

more difficult to cope with when the rest of the household load is also high.

The peak powers of the combined load of all dishwashers are lower than those of washing machines and tumble dryers, being only $11 \mathrm{~kW}$ for all seasonal periods. The highest two minutes of peak power is for all seasonal periods more or less the same, where for the other wet appliances there were much larger differences. The dishwashers have between $2.5 \mathrm{~min}$ (summer) and $13 \mathrm{~min}$ (winter) above $10 \mathrm{~kW}$ power demand. The power demand of all dishwashers combined is over $4 \mathrm{~kW}$ from $25 \mathrm{~h}$ in the summer to $42 \mathrm{~h}$ in the winter. For the winter that means $7 \%$ of the total time the power of all dishwashers exceeds $4 \mathrm{~kW}$.

The seemingly discrete values in the load curve, or 'steps' from $200 \mathrm{~W}$ to $2 \mathrm{~kW}$, and from $2.4 \mathrm{~kW}$ to $4 \mathrm{~kW}$, are due to the discrete values in the power profiles from the dishwashers, being either $2000 \mathrm{~kW}$ or $200 \mathrm{~W}$, with very few dishwashers having power demands within these two values.

\subsection{Peak reduction}

Reduction of peak power demand from households can be realized using DSM of wet appliances (cf. Fig. 4), as most cycles do not necessarily have to be carried out at a specific time. As the length of the peak in households is set at three hours in this research, it is assumed that households are able to shift the start moment of their appliances out of this three-hour peak. Thus, the maximum potential for peak reduction can be defined, in relation to the assumptions made. Note, however, that the amount of peak reduction obviously depends on the willingness of households to adapt their use of wet appliances [18,25,32].

The effect of removal of power demand from wet appliances from peak hours on the absolute peak on the day (denoted as 'peak moment power') and the average power demand $1.5 \mathrm{~h}$ before and $1.5 \mathrm{~h}$ after this absolute peak (denoted as 'average peak power') is calculated first for each separate appliance group and then for all appliance groups together.

\subsubsection{Peak moment power}

The first step is identifying the current state of peak moment and peak period for the three seasonal periods. This is done for every separate day. The results are shown in Fig. 7 as boxplot diagrams.

Both peak moment power and peak average power in winter are in general much higher compared to the spring and summer

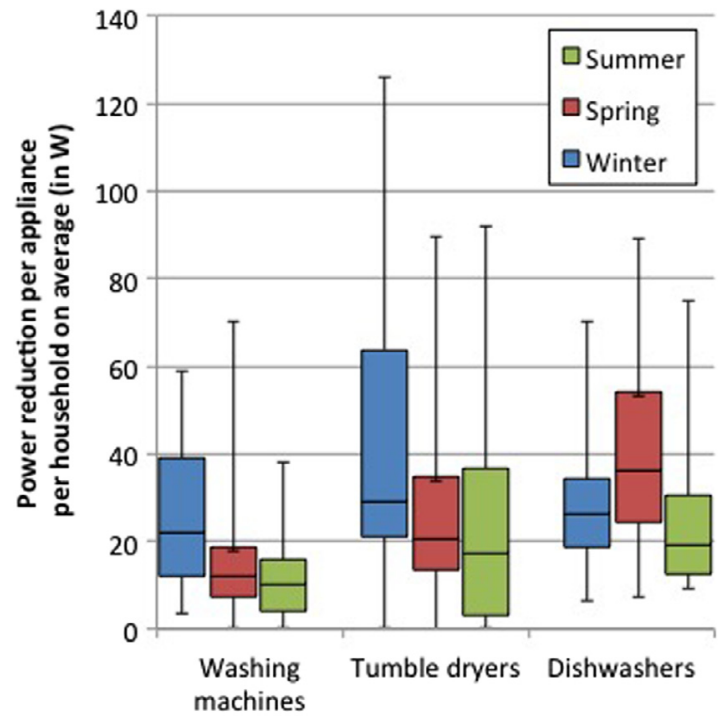

Fig. 8. Reduction of average peak power per household per appliance group per seasonal period.

seasonal periods, while spring is a little higher than summer. This is correlated with number of uses as shown in Table 3.

When shifting the power demand to another moment, the reduction of the peak moment power can be calculated by first determining the new peak moment of the day and subsequently subtracting that power from the original peak moment power. This results in median peak moment reduction per household of 2-14 W, 0-44 W, and 44-53 W for washing machines, tumble dryers, and dishwashers, respectively, with considerable spread. Taking the median as indicator of the appliance with the highest potential, the dishwasher has the best potential of the wet appliances.

\subsubsection{Peak power reduction}

The same method is applied to analyze the effect of removing wet appliances use in the peak hours on the peak average. The results are depicted in Fig. 8, and show that the reduction potential of the average peak power per household varies between 0 and $127 \mathrm{~W}$. There are large differences between the days within seasonal periods, which make the use of wet appliances for peak reduction hard to rely on for a DSO. The medians of the average peak reduction potentials per household range between 12 and $22 \mathrm{~W}$ for the washing machines, between 18 and $28 \mathrm{~W}$ for the tumble dryers and between 19 and $37 \mathrm{~W}$ for the dishwashers.

Differences between appliance groups are quite small in the winter period. The medians of all appliance groups are more or less equal, while only the range of the tumble dryer in winter is much higher compared to the washing machine and dishwasher. In spring and summer it is obvious that for reducing the average peak power the washing machine is less suitable than the tumble dryer and dishwasher. The median of the washing machine in these two seasonal periods is lower than those of the tumble dryer and dishwasher and the range is also lower. While the washing machine and tumble dryer have multiple season periods where for some days no or almost no reduction potential exists, the dishwashers do always have at least $7 \mathrm{~W}$ average peak power reduction potential for each household on average. As this only constitutes between $1 \%$ and $2 \%$ of the average peak power, the impact is low. The medians of winter and summer period are almost equal for tumble dryers and dishwashers, but the median in the spring is much higher for dishwashers. Based on the medians and the minimums of all three appliance groups, dishwashers have the highest potential for average peak reduction. 


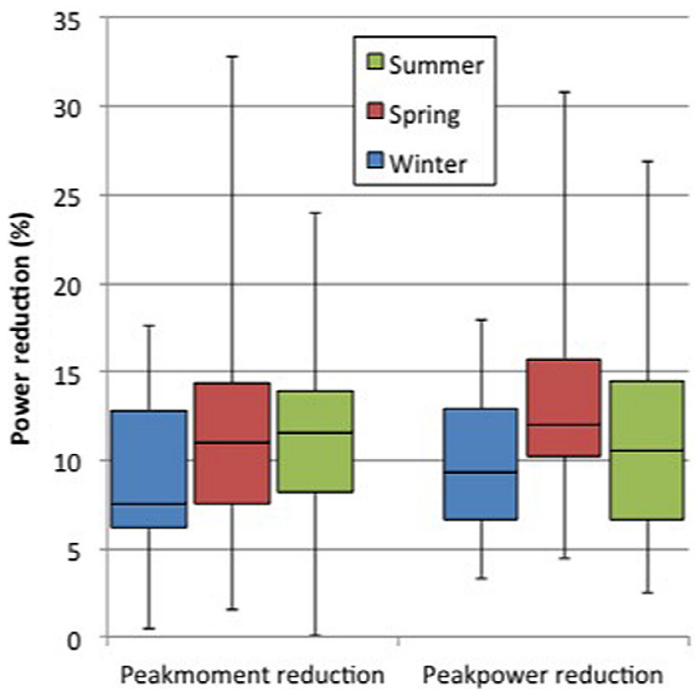

Fig. 9. Relative reduction of peak moment power and average peak power for appliances combined per season.

The appliances could be used for peak reduction at the same time, which would have much more practical implications but would require more willingness of the inhabitants to reduce their wet appliance use. The total peak moment power and average peak power reduction potential is calculated by removing all appliance groups from the total power demand at the same time, yielding a maximum potential limit. This is related to the actual peak moment power and average peak power to find the relative power reduction possible, as shown in Fig. 9. This reflects that both peak moment power and average peak power reduction are around $10 \%$, which albeit small is still a significant DSM potential. This thus requires all households to refrain from using any wet appliance within the three-hour peak period. There are large differences in relative power reduction, making wet appliances not a very reliable way to reduce peak power demand, as one day the reduction potential may be much lower or much higher than the next day. It remains to be determined if benefits of peak reduction outweigh disadvantages for households.

The financial benefit of $10 \%$ peak reduction for the system is hard to determine. This will be dependent on the load problems of the DSO, the lines connecting the specific area and intended investments in new grid infrastructure. Introduction of intelligent grids in the Netherlands has been estimated in a cost benefit analysis to be economically viable [45]. Being able to reduce peak load is very likely to constitute some financial gain from, either from the DSO or from utility or aggregator companies. It is however important that all households cooperate to achieve this potential and thus some sort of organization has to be established to obtain the calculated peak reduction potential. Especially in cases where these high peaks are only expected one or twice a year, it is very expensive to invest in grid reinforcements. In these cases DSM really adds value and the financial benefits of $10 \%$ peak reduction can be substantial in these cases.

\subsection{PV self-consumption}

\subsubsection{Seasonal analysis}

Increased PV self-consumption can be achieved by increasing power demand during sunny hours. Usage of appliances should thus be rescheduled to those hours. In this research it is assumed that all homeowners are willing to change their behavior to increase their self-consumption, either manually or automatically by means of ICT. The inhabitants will have to fill up their appliances

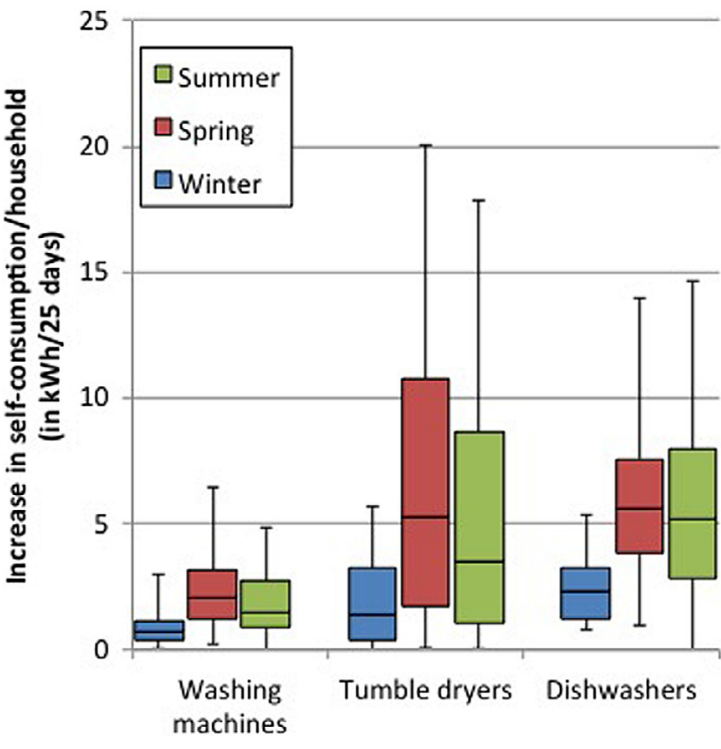

Fig. 10. Increase in PV self-consumption per household per season.

in the morning and wait for the peak in solar power, after which the appliance is turned on. This would require perfect solar forecasting, and while clear progress has been made [46-48] errors in forecasting especially in partly overcast days may prohibit solardriven DSM. Note that the 3-kWp PV systems generate $47.6 \mathrm{kWh}$, $240.6 \mathrm{kWh}$, and $304.1 \mathrm{kWh}$ for the 25-day periods defined as winter, spring, and summer, respectively.

While washing machines and dishwashers can be rescheduled quite easily, rescheduling tumble dryers is linked to washing machine use. The earliest starting time of tumble dryers is set at 11:00, to allow for completing a washing machine cycle powered by PV electricity. Fig. 10 shows the increase in PV self-consumption for the appliance groups, per season. The results reveal large differences between the different wet appliances. The washing machines have a low PV self-consumption potential throughout all seasonal periods, with the medians below $3 \mathrm{kWh}$ per 25-day period. This will be mainly due to the fact that washing machines do not require a lot of kWh per cycle and most washing machine cycles are already started in the middle of the day when solar production is high (in our dataset). On top of that, many households use the washing machine only a few days a week, but in those days they use the appliances multiple times, while we allowed only one to be rescheduled. Low PV self-consumption potential thus is found ranging between 0 and $6 \mathrm{kWh}$ per period of 25 days. As expected the winter has the lowest potential due to low solar irradiation, while the spring has for all quartiles a better self-consumption then the summer.

The tumble dryers show a more promising amount of kWh of self-consumption. While the potential is obviously low in winter, the potential is 20 and $18 \mathrm{kWh}$ per 25 days in spring and summer respectively. The spread of self-consumption potential for tumble dryers is very high, signifying high differences between the individual households. In spring, the first two quartiles of households have the same spread ( $5 \mathrm{kWh}$ ) as the whole third quartile, and the first three quartiles have the same spread $(10 \mathrm{kWh})$ as the whole fourth quartile. This indicates a situation where the PV selfconsumption pattern is household specific: no good guideline can be given for a 'typical' household with a tumble dryer, as the results from this analysis show very differing potentials. As with the washing machines, the spring has more PV self-consumption potential than the summer, which can be explained by the lower amount of tumble dryer cycles in the summer. The amount of cycles that are rescheduled is rather low (between 5 and 7 days on average) because the tumble dryer is mostly used on one or two days a week, 
Table 4

Relative increase PV self-consumption (unit: median \% (range)).

\begin{tabular}{llll}
\hline Appliance groups & Winter & Spring & Summer \\
\hline Washing machines & $5.8(0.1-17.4)$ & $1.4(0.2-5.6)$ & $0.8(0.0-3.4)$ \\
Tumble dryers & $5.4(0.0-36.6)$ & $2.4(0.1-12.7)$ & $1.4(0.0-8.1)$ \\
Dishwashers & $15.6(2.8-40.5)$ & $4.5(0.5-7.3)$ & $2.8(0.0-7.1)$ \\
\hline
\end{tabular}

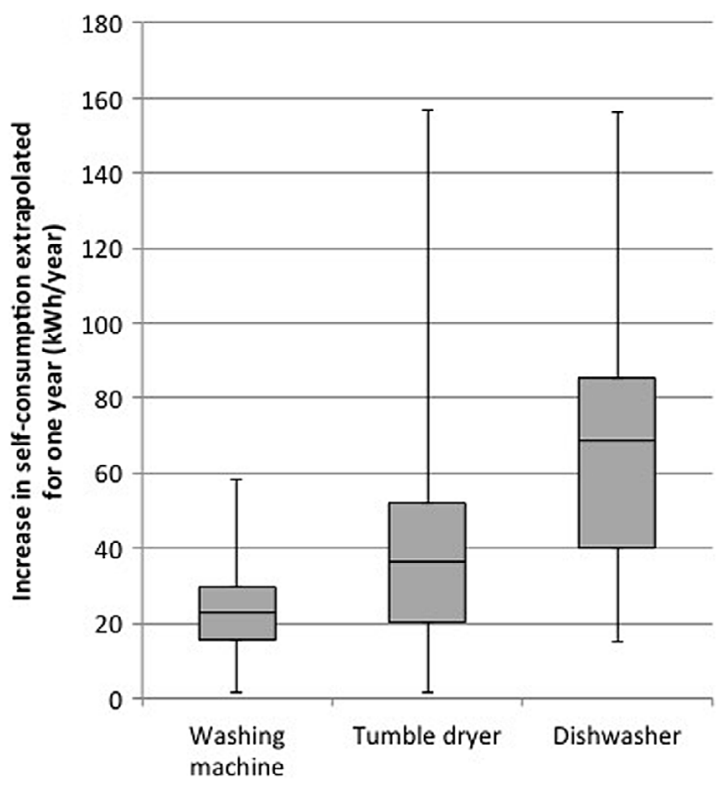

Fig. 11. Increase in annual PV self-consumption per household.

which reduces the possibilities for rescheduling. This would imply a higher potential if the tumble dryer could be rescheduled to the next day.

The dishwasher's PV self-consumption potential is the lowest in winter, while the median of $2.5 \mathrm{kWh}$ is the highest of winter potentials of the wet appliances. The medians of spring and summer are twice as high, around $5 \mathrm{kWh}$ per 25 days. The highest potentials for households go up to $14.5 \mathrm{kWh}$ in the spring and summer, but this can be attributed to households with very high dishwasher use. The mean is higher in the spring compared to the summer, which could be explained due to the lower amount of cycles in the summer.

The results show that the amount of kWh PV self-consumption depends on the season. The relative increase in self-consumption is shown in Table 4. It is clear that while the absolute amount of $\mathrm{kWh}$ increase in self-consumption is low in the winter compared to spring and winter, the relative increase is much higher in the winter compared to the other two seasonal periods. All winter medians are above 5\% increase in PV self-consumption and are even above $15 \%$ for dishwashers in winter season.

\subsubsection{Extrapolation to yearly potential}

The impact of using wet appliances on PV self-consumption on a yearly basis is determined using extrapolation, on a per household basis. The results are shown in Fig. 11 in absolute numbers.

Large differences between wet appliance groups are apparent. The washing machine clearly has the lowest potential, which is mainly the result of these appliances already being used during hours with large solar irradiance. The median household potential is an increase of $23 \mathrm{kWh}$ in self-consumption, which is the equivalent of about 26 washing machine cycles. Other important factors responsible for the low potential are the relative low energy use of a washing machine cycle and the bundling of multiple washing cycles on one day, while only one cycle can be rescheduled. The tumble dryer has a higher range of the potentials between households, with the minimum potential being comparable to the minimum potential of the washing machine, but the maximum potential being more than 2.5 times larger than the maximum of the washing machine. The median household potential is $38 \mathrm{kWh}$, equivalent to about 15 tumble dryer cycles. This higher potential is likely due to the high energy use of tumble dryer cycles in combination with the start times of tumble dryers typically being later on the day compared to washing machine cycles. The dishwasher has the highest potential, ranging between 17 and $157 \mathrm{kWh}$. The median household potential for dishwashers is $68 \mathrm{kWh}$, which is three times as high as the washing machines median and nearly two times as high as the tumble dryers' median. The median of $68 \mathrm{kWh}$ is equivalent to 57 dishwasher cycles. While the energy use per cycle of the dishwasher is rather low compared to the tumble dryer, the time of use is often during low or no solar power production (see Fig. 5), which results in larger increases in PV self-consumption if the cycle is shifted towards solar hours. Another beneficial factor for the potential of dishwashers is the usage pattern of dishwashers, which displays much less frequent multiple cycles a day than washing machines and tumble dryers.

The potentials of PV self-consumption are shown per appliance type, while these potentials can be summed up to obtain the total potential, which would be $129 \mathrm{kWh}$ per household, and which is about $6 \%$ of the annual household demand. In practice the total potential of using multiple appliances would be lower due to interaction problems: the appliances are optimized for utilization at the highest PV production hours. If one of the appliances is already used this way, the second appliance that is being rescheduled that day is unable to make use of this highest PV solar production peak.

\section{Discussion}

The aim of this research was to analyze the potential of wet appliances for peak reduction and PV self-consumption. This was done based on some assumptions, which should be reviewed. The first main assumption has been that all appliances can be used for both peak reduction and PV self-consumption; hence results obtained are maximum potentials. In practice, it is very unlikely that all households are able to and willing to cooperate and reschedule their appliances [18,25,32]. Another important assumption is perfect forecasting of solar production. The scripts developed in this research have rescheduled the appliances to the optimal time of the day. Currently it is not possible to perfectly predict the solar power during the day, thus limiting the potentials. However, forecast errors on sunny days, which are most suitable for demand shifting, are small. Moreover, developed forecast methods show limited improved forecasts over persistence forecasting on such days [ $46-49$ ]. Therefore we estimate $\sim 10 \%$ lower potential due to not perfect solar forecasts. A third important assumption is that inhabitants were able to reschedule one appliance each day. On the one hand this could result in a lower potential as some households may be able to reschedule multiple cycles each day. On the other hand, some households may be unable to reschedule even one cycle as they may be absent and their appliance does not have a timer setting (note that we did not take smart appliances into account, as they were not present in our test data set). While these assumptions provide some drawbacks to the outcomes of this research, these assumptions are made to determine the magnitude of the absolute and relative potential of these wet appliances.

The dataset in this research is quite specific and does not necessarily reflect all households in the Netherlands. The households in this dataset consisted of mainly families in rather large dwellings. Electricity demand and appliance use at smaller dwellings or smaller households can be different, influencing the potential for these types of households. The usage pattern of 
appliances in this research is likely somewhat higher than average in families, as there are typically more dirty clothes and dishes when there are more people in the household.

The amount of households incorporated may not be sufficient to draw general conclusions also applicable to other districts but it does show that large differences between households exist due to differences in the usage pattern of the appliances. Some households have very high amount of cycles per appliance and these household have a reasonable PV self-consumption potential, but at the same time some households rarely use their appliance, resulting in a very low potential. An important recommendation for further research would be to increase the amount of households under study and appliances as well as focusing on the households with a more regular appliance use of a couple of cycles per week.

The potential of DSM is determined based on the measured use patterns. As in this case the washing machine is not often used during the evening hours, the potential and the value of DSM for these wet appliances is relatively low. This means that for specific communities or households with other user patterns the potential might differ from the potential calculated in this situation. This also explains that others have found higher DSM potential in similar studies [18]. Also, Widen [28] shows higher DSM potential, i.e., $200 \mathrm{kWh}$ for households in Sweden, while the present research found $129 \mathrm{kWh}$. The difference could be explained due to the higher installed PV capacity on those households (i.e. 3-9 kWp).

While the dataset used in this research has a unique time resolution of $10 \mathrm{~s}$, there were some issues while analyzing these data. Data were not available for some days, due to problems with the connection to the database. These days had to be omitted in the research and larger data-gaps in other months resulted in the use of seasonal periods of 25 days instead of the whole year. Future research should also focus on the analysis of the whole year, especially taking into account the autumn, which is not done in this research due to unavailability of data. This research has tried to exclude households that seemed to have incorrect results, which resulted in about half of the households available in the dataset included in this research.

While the results of the PV self-consumption analyses show that the potential of wet appliances is not very high, it is important to note that these appliances are a rather easy method to increase PV self-consumption. Most households, if they are willing to adapt, are able to utilize this potential without investments or major changes in behavior. Once net metering is abolished, using wet appliances will likely be the most profitable method of increasing self-consumption due to lack of necessary investments. Note that storage options will require quite an investment, but could provide for a much more substantial increase in PV selfconsumption. Future research could focus on the willingness of households to increase their PV self-consumption by rescheduling their appliances, especially as the financial gains are not likely to be substantial. It should also be noted that DSM with wet appliances could provide for an interesting combination with storage, as peaks in solar production could possibly be used by these appliances, but this requires control equipment to coordinate between the storage and wet appliance use.

Another interesting option for further research would be to determine DSM potential of cold appliances (freezer, refrigerator) as these can be cooled deeper if the minimum temperature has not been reached. DSM with these kinds of appliances requires some form of temperature control to make sure the temperature does not increase to unacceptable levels. However, this would increase PV self-consumption. Finally, DSM potential of electric heat pumps [50] and electric vehicles [11] is large.

\section{Conclusions}

This research has focused on the possibilities of demand side management in the residential sector in the Netherlands using wet appliances: washing machine, tumble dryer and dishwasher. It is expected that most households are able to reschedule these appliances and thereby change their demand pattern to match the renewable supply of solar panels. This research is based on a case study in Amersfoort, where power data for households, wet appliances and solar panels where available with a 10-s resolution. The research analyzed data for 42 households, 39 solar panel systems, 42 washing machines, 23 tumble dryers and 24 dishwashers. The households were mainly large terrace houses inhabited by families. Power consumption and production data was used to identify three separate seasonal periods of 25 days: winter, spring and summer. All three types of wet appliances have been analyzed on usage patterns, such as moment of use, amount of cycles per appliance and simultaneity between different appliances. Subsequently, DSM potential has been calculated for peak reduction and PV self-consumption.

It was found that the usage patterns of washing machine and dishwasher have 'bulk' hours in the morning and afternoon, while dishwashers are mainly used after dinner and before bedtime. Due to the main usage times being outside of the evening peak of households, the potential for peak reduction is found low for washing machines. Also, peak reduction depends heavily on the day, and large variation in DSM potential is found. PV self-consumption increase by shifting usage is low due to the fact that washing machine use already is high around noon. For tumble dryers, as these are used after the washing machine, DSM potential is higher. The potential for peak reduction of dishwashers is the highest of all wet appliances, due to the relative high use in the evening.

All three wet appliances have some potential for both peak reduction and PV self-consumption. For peak reduction the ranges of potential are very large, going from 0 to 5 times the median potential. For the DSO or aggregator company it is important to be able to rely on the potential reduction if DSM was implemented, without having to confront some days without any peak reduction. Applying this form of DSM is quite easy, assuming inhabitants are willing to participate, by assigning the hours where peak power demand is expected and then requesting all households to refrain from using the wet appliances during that time period. All appliances used together for peak reduction would be able to reduce around $100 \mathrm{~W}$ of peak moment and between 50 and $75 \mathrm{~W}$ of average peak power (per household on average). While this requires all households to defer from using any of their wet appliances for three hours straight, this could result in a peak reduction of about $10 \%$.

PV self-consumption has been calculated from a household perspective. Potentials are in absolute terms higher in spring and summer due to higher solar irradiance, but high in relative terms in the winter. The annual extrapolated potentials are the highest for dishwashers (median $68 \mathrm{kWh} /$ year), followed by tumble dryers (38 kWh/year) and washing machines (median $23 \mathrm{kWh} /$ year). These amounts add up to between $1 \%$ and $4 \%$ of the total amount of $\mathrm{kWh}$ returned to the grid. Large differences between minimum and maximum potential show that the real potential for a household depends strongly on the usage pattern and current usage times. Combining these appliances would result in a total median potential of up to $129 \mathrm{kWh}$ per year of increased PV selfconsumption, which is $6 \%$ of annual household demand. Hence, DSM by means of wet appliances is low.

\section{Acknowledgments}

This work was part of the project Smart Grids: Rendement voor Iedereen ("Smart Grids: benefit for all"), which was funded by the Economic Board Utrecht, Utrecht city council, Amersfoort city council, and the Province of Utrecht.

\section{Appendix}

Tables A.1-A.7. 
Table A.1

Iteration sequence for washing machine cycle analysis.

\begin{tabular}{llll}
\hline Step & Sequence & Variable extracted & Variable explanation \\
\hline 1 & Iteration start, $t=0$ & & \\
2 & $t=t+1$ & $t_{W 1}$ & Bulk moment start (time and date) \\
3 & $P\left(t_{1}\right)>1500 \mathrm{~W}$ & & \\
4 & Continue iteration, $t=t+1$ & $t_{W 2}$ & Bulk moment end (time and date) \\
5 & If $P\left(t_{2}\right)<1500 \mathrm{~W}$ & $L_{W}$ & Variable explanation \\
6 & $L_{w}=t_{2}-t_{1}$ & $P_{W \_a v g}$ & Bulk moment average power \\
7 & $P_{w \_a v g}=\overline{\left\{P\left(t_{1}\right), P\left(t_{1}+1\right), \ldots, P\left(t_{2}\right)\right\}}$ & & \\
8 & Continue iteration from step 2 &
\end{tabular}

Table A.2

Iteration sequence for tumble dryer cycle analysis.

\begin{tabular}{rlll}
\hline Step & Sequence & $\begin{array}{l}\text { Variable } \\
\text { extracted }\end{array}$ & Explanation \\
\hline 1 & Iteration start, $t=0$ & & \\
2 & $t=t+1$ & & \\
3 & $P\left(t_{1}\right)>1800 \mathrm{~W}$ & $t_{t 1}$ & Bulk moment 1 start (time and date) \\
4 & Continue iteration, $t=t+1$ & $t_{t 2}$ & \\
5 & If $P\left(t_{2}\right)<2000 \mathrm{~W}$ & $L_{t 1}$ & Bulk moment 1 end (time and date) \\
6 & $L_{t 1}=t_{2}-t_{1}$ & $P_{t 1 \_a v g}$ & Bulk moment 1 length \\
7 & $P_{t 1 \_a v g}=\left\{P\left(t_{1}\right), P\left(t_{1}+1\right), \ldots, P\left(t_{2}\right)\right\}$ & $t_{t 2}$ & Bulk moment 1 average power \\
8 & If $P\left(t_{2}\right)>700 \mathrm{~W}$ & & Bulk moment 2 start (time and date) \\
9 & Continue iteration, $t=t+1$ & $t_{t 3}$ & Bulk moment 2 end (time and date) \\
10 & If $P\left(t_{3}\right)<700 \mathrm{~W}$ & $L_{t 2}$ & Bulk moment 2 length \\
11 & $L_{t 2}=t_{3}-t_{2}$ & $P_{t 2 \_a v g}$ & Bulk moment 2 average power \\
12 & $P_{t 2 \_a v g}=\left\{P\left(t_{2}\right), P\left(t_{2}+1\right), \ldots, P\left(t_{3}\right)\right\}$ & $L_{t, t o t}$ & Total length of both bulk moments \\
13 & $L_{t, t o t}=L_{t 1}+L_{t 2}$ & & \\
14 & Continue iteration from step 2 & & \\
\hline
\end{tabular}

Table A.3

Iteration sequence for dishwasher cycle analysis.

\begin{tabular}{rlll}
\hline Step & Sequence & $\begin{array}{l}\text { Variable } \\
\text { extracted }\end{array}$ & Explanation \\
\hline 1 & Iteration start, $t=0$ & & \\
2 & $t=t+1$ & $t_{d 1}$ & Bulk moment 1 start (time and date) \\
3 & If $P\left(t_{1}\right)>1000 \mathrm{~W}$ & & \\
4 & Continue iteration, $t=t+1$ & $t_{d 2}$ & Bulk moment 1 end (time and date) \\
5 & If $P\left(t_{2}\right)<1000 \mathrm{~W}$ & $L_{d 1}$ & Bulk moment 1 length \\
6 & $L_{d 1}=t_{2}-t_{1}$ & $P_{d 1 \_a v g}$ & Bulk moment 1 average power \\
7 & $P_{d 1 \_a v g}=\left\{P\left(t_{1}\right), P\left(t_{1}+1\right), \ldots, P\left(t_{2}\right)\right\}$ & & \\
8 & Continue iteration, $t=t+1$ & $t_{d 3}$ & Bulk moment 2 start (time and date) \\
9 & If $P\left(t_{3}\right)>1000 \mathrm{~W}$ & & Bulk moment 2 end (time and date) \\
10 & Continue iteration, $t=t+1$ & $t_{d 4}$ & Bulk moment 2 length \\
11 & If $P\left(t_{4}\right)<1000 \mathrm{~W}$ & $L_{d 2}$ & Bulk moment 2 average power \\
12 & $L_{d 2}=t_{4}-t_{3}$ & $P_{d 2 \_a v g}$ & Total length of cycle \\
13 & $P_{d 2 \_a v g}=\left\{P\left(t_{3}\right), P\left(t_{3}+1\right), \ldots, P\left(t_{4}\right)\right\}$ & $L_{d, t o t}$ & \\
14 & $L_{d, t o t}=t_{4}-t_{1}$ & & \\
15 & Continue iteration from step 2 & & \\
\hline
\end{tabular}

Table A.4

Adapted iteration sequence for dish washers with more than two $2000 \mathrm{~W}$ peaks.

\begin{tabular}{llll}
\hline Step & Sequence & Variable extracted & Explanation \\
\hline 13 & $P_{d 2 \_a v g}=\overline{\left\{P\left(t_{3}\right), P\left(t_{3}+1\right), \ldots, P\left(t_{3}\right)\right\}}$ & $P_{d 2 \_a v g}$ & Bulk moment 2 average power \\
14 & If $P\left(t_{4}\right)<10 \mathrm{~W}$ & & \\
15 & Continue iteration from step 8 add up length & & \\
& \& power to $L_{d 2}$ and $P_{d 2 \_a v g}$ & & Total length of cycle \\
16 & If $P\left(t_{4}\right)>10 \mathrm{~W}$ & $L_{d, t o t}$ & \\
17 & $L_{d, t o t}=t_{4}-t_{1}$ & & \\
18 & Continue iteration from step 2 &
\end{tabular}


Table A.5

PV self-consumption algorithm for washing machines.

\begin{tabular}{|c|c|}
\hline Step & Sequence \\
\hline 1 & Start with first day \\
\hline \multirow[t]{3}{*}{2} & Find whether there is a cycle during this day \\
\hline & If so, retrieve power profile for that day $\rightarrow$ original daily profile. \\
\hline & If not, continue to step 10 \\
\hline 3 & Identify amount of cycles during this day \\
\hline \multirow[t]{3}{*}{4} & $\begin{array}{l}\text { If only } 1 \text { cycle: subtract cycle profile from original daily power profile } \\
\rightarrow \text { reduced daily profile }\end{array}$ \\
\hline & If $>1$ cycle: Find the cycle with the lowest PV consumption \\
\hline & $\begin{array}{l}\text { subtract only that cycle profile from original daily power profile } \\
\rightarrow \text { reduced daily profile }\end{array}$ \\
\hline \multirow[t]{3}{*}{5} & If there is only 1 cycle \\
\hline & Find the period of 15 min with highest net power production from reduced daily profile \\
\hline & $\begin{array}{l}\text { If }>1 \text { cycle: find the period of } 15 \text { min with highest net power production from reduced daily profile, which is not within } 1.5 \text { h of any other cycle start } \\
\text { moment }\end{array}$ \\
\hline 6 & Re-index the profile to match the start of the cycle to the start of this 15 -min period \\
\hline 7 & $\begin{array}{l}\text { Add the new cycle profile to the reduced daily profile } \\
\rightarrow \text { optimized daily profile }\end{array}$ \\
\hline \multirow[t]{2}{*}{8} & Count the amount of kWh delivered to the grid in the original daily power profile \\
\hline & Count the amount of kWh delivered to the grid in the optimized daily profile \\
\hline \multirow[t]{2}{*}{9} & Subtract optimized kWh delivered from the original kWh delivered \\
\hline & $\rightarrow$ This difference is the increase in PV self-consumption \\
\hline \multirow[t]{2}{*}{10} & Go to next day \\
\hline & Continue with step 2 \\
\hline
\end{tabular}

Table A.6

PV self-consumption algorithm for tumble dryers.

\begin{tabular}{|c|c|}
\hline Step & Sequence \\
\hline 1 & Start with first day \\
\hline \multirow[t]{3}{*}{2} & Find whether there is a cycle during this day \\
\hline & If so, retrieve power profile for that day \\
\hline & $\rightarrow$ original daily profile. If not, continue to step 10 \\
\hline 3 & Identify amount of cycles during this day \\
\hline \multirow[t]{2}{*}{4} & $\begin{array}{l}\text { If only } 1 \text { cycle: subtract cycle profile from original daily power profile } \\
\rightarrow \text { reduced daily profile }\end{array}$ \\
\hline & $\begin{array}{l}\text { If }>1 \text { cycle: Find the cycle with the lowest PV consumption subtract only that cycle profile from original daily power profile } \\
\rightarrow \text { reduced daily profile }\end{array}$ \\
\hline \multirow[t]{2}{*}{5} & $\begin{array}{l}\text { If there is only } 1 \text { cycle: Find the period of the length of the displaced cycle minutes with highest net power production from reduced daily profile. This } \\
\text { period should be later than 11:00 }\end{array}$ \\
\hline & $\begin{array}{l}\text { If }>1 \text { cycle: find the period of the length of the displaced cycle with highest net power production from reduced daily profile, which is not within } 2 \text { h of } \\
\text { any other cycle start moment. This period should be later than 11:00 }\end{array}$ \\
\hline 6 & Re-index the profile to match the start of the cycle to the start of this 15 -min period \\
\hline 7 & $\begin{array}{l}\text { Add the new cycle profile to the reduced daily profile } \\
\rightarrow \text { optimized daily profile }\end{array}$ \\
\hline \multirow[t]{2}{*}{8} & Count the amount of kWh delivered to the grid in the original daily power profile \\
\hline & Count the amount of kWh delivered to the grid in the optimized daily profile \\
\hline 9 & $\begin{array}{l}\text { Subtract optimized kWh delivered from the original kWh delivered } \\
\rightarrow \text { This difference is the increase in PV self-consumption }\end{array}$ \\
\hline \multirow[t]{2}{*}{10} & Go to next day \\
\hline & Continue with step 2 \\
\hline
\end{tabular}

Table A.7

PV self-consumption algorithm for dishwashers.

\begin{tabular}{|c|c|}
\hline Step & Sequence \\
\hline 1 & Start with first day \\
\hline \multirow[t]{3}{*}{2} & Find whether there is a cycle during this day, or the previous day after 17:00 \\
\hline & If so, retrieve power profile for that day \\
\hline & $\rightarrow$ original daily profile. If not, continue to step 10 \\
\hline 3 & Identify amount of cycles during and previous day after 17:00 \\
\hline \multirow[t]{2}{*}{4} & $\begin{array}{l}\text { If only } 1 \text { cycle: subtract cycle profile from original daily power profile } \\
\rightarrow \text { reduced daily profile }\end{array}$ \\
\hline & $\begin{array}{l}\text { If }>1 \text { cycle: Find the cycle with the lowest PV consumption subtract only that cycle profile from original daily power profile } \\
\rightarrow \text { reduced daily profile }\end{array}$ \\
\hline 5 & $\begin{array}{l}\text { If there is only } 1 \text { cycle: Find the period of the length of the displaced cycle minutes with highest net power production from reduced daily profile. } \\
\text { If }>1 \text { cycle: find the period of the length of the displaced cycle with highest net power production from reduced daily profile, which is not within the } \\
\text { length of the displaced cycle of any other cycle start moment }\end{array}$ \\
\hline 6 & Re-index the profile to match the start of the cycle to the start of this period \\
\hline 7 & $\begin{array}{l}\text { Add the new cycle profile to the reduced daily profile } \\
\rightarrow \text { optimized daily profile }\end{array}$ \\
\hline \multirow[t]{2}{*}{8} & Count the amount of kWh delivered to the grid in the original daily power profile from 17:00 of the previous day to $17: 00$ of this day \\
\hline & Count the amount of kWh delivered to the grid in the optimized daily profile from 17:00 of the previous day to 17:00 of this day \\
\hline \multirow[t]{2}{*}{9} & Subtract optimized kWh delivered from the original kWh delivered \\
\hline & $\rightarrow$ This difference is the increase in PV self-consumption \\
\hline \multirow[t]{2}{*}{10} & Go to next day \\
\hline & Continue with step 2 \\
\hline
\end{tabular}




\section{References}

[1] IEA-PVPS, 2015 Snapshot of Global PV Markets, 2016

[2] A. Battaglini, J. Lilliestam, A. Haas, A. Patt, Development of SuperSmart Grids for a more efficient utilisation of electricity from renewable sources, J. Cleaner Prod. 17 (2010) 911-918.

[3] M. Lunde, I. Røpke, E. Heiskanen, Smart grid: hope or hype, Energy Effic. (2016) $545-562$.

[4] S. Darby, J. Strömback, M. Wilks, Potential carbon impacts of smart grid development in six European countries, Energy Effic. 6 (2013) 725-739.

[5] A. Mahmood, N. Javaid, M.A. Khan, S. Razzaq, An overview of load management techniques in smart grid, Int. J. Energy Res. 39 (2015) 1437-1450.

[6] M. Wissner, The smart grid - a saucerful of secrets? Appl. Energy 88 (2011) 2509-2518.

[7] C.W. Gellings, M. Samotyl, Smart grid as advanced technology enabler of demand response, Energy Effic. 6 (2013) 685-694.

[8] G. Strbac, Demand side management: Benefits and challenges, Energy Policy 36 (2008) 4419-4426.

[9] G.P.J. Verbong, S. Beemsterboer, F. Sengers, Smart grids or smart users? Involving users in developing a low carbon electricity economy, Energy Policy 52 (2013) 117-125.

[10] P. Mesaric, S. Krajcar, Home demand side management integrated with electric vehicles and renewable energy sources, Energy Build. 108 (2015) 1-9.

[11] M. Van der Kam, W. Van Sark, Smart charging of electric vehicles with photovoltaic power and vehicle-to-grid technology in a microgrid; a case study, Appl. Energy 152 (2015) 20-30.

[12] O. Erdinc, N.G. Paterakis, I.N. Pappi, A.G. Bakirtzis, J.P.S. Catalão, A new perspective for sizing of distributed generation and energy storage for smart households under demand response, Appl. Energy 143 (2015) 26-37.

[13] P. Finn, M. O'Connell, C. Fitzpatrick, Demand side management of a domestic dishwasher: Wind energy gains, financial savings and peak-time load reduction, Appl. Energy 101 (2013) 678-685.

[14] S. Gyamfi, S. Krumdieck, Scenario analysis of residential demand response at network peak periods, Electr. Power Syst. Res. 93 (2012) 32-38.

[15] K. Vanthournout, B. Dupont, W. Foubert, C. Stuckens, S. Claessens, An automated residential demand response pilot experiment, based on dayahead dynamic pricing, Appl. Energy 155 (2015) 195-203.

[16] R. D'hulst, W. Labeeuw, B. Beusen, S. Claessens, G. Deconinck, K. Vanthournout, Demand response flexibility and flexibility potential of residential smart appliances: Experiences from large pilot test in Belgium, Appl. Energy 155 (2015) 79-90.

[17] R. Stamminger, V. Anstett, The effect of variable electricity tariffs in the household on usage of household appliances, Smart Grid Renewable Energy 4 (2013) 353-365.

[18] C.B.A. Kobus, E.A.M. Klaassen, R. Mugge, J.P.L. Schoormans, A real-life assessment on the effect of smart appliances for shifting households' electricity demand, Appl. Energy 147 (2015) 335-343.

[19] P. Palensky, D. Dietrich, Demand side management: Demand response, intelligent energy systems, and smart loads, IEEE Trans. Ind. Inf. 7 (2011) 381.

[20] M. Rastegar, M. Fotuhi-Firuzabad, F. Aminifar, Load commitment in a smart home, Appl. Energy 96 (2012) 45-54.

[21] M. Muratori, B.A. Shuelke-Leech, G. Rizzoni, Role of residential demand response in modern electricity markets, Renewable Sustainable Energy Rev. 33 (2014) 546-553.

[22] M.H.J. Weck, J. Van Hooff, W.G.J.H.M. van Sark, Review of barriers to the introduction of residential demand response: a case study in the Netherlands, Int. J. Energy Res. (2017) http://dx.doi.org/10.1002/er.3683, in press.

[23] C. Timpe, Smart Domestic Appliances Supporting the System Integration of Renewable Energy, 2009. http://www.smart-a.org/SmartA_Project_Final_ Brochure_2009.pdf (last accessed 16.12.16).

[24] M. Broman Toft, G. Schuitema, J. Thøgersen, Responsible technology acceptance: Model development and application to consumer acceptance of Smart Grid technology, Appl. Energy 134 (2014) 392-400.

[25] C.B.A. Kobus, R. Mugge, J.P.L. Schoormans, Washing when the sun is shining! How users interact with a household energy management system, Ergonomics 139 (2013) 451-462.

[26] P. Warren, A review of demand-side management policy in the UK, Renewable Sustainable Energy Rev. 29 (2014) 941-951.

[27] A. Tascikaraoglu, A.R. Boynuegri, M. Uzunoglu, A demand side management strategy based on forecasting of residential renewable sources: A smart home system in Turkey, Energy Build. 80 (2014) 309-320.
[28] J. Widén, Improved photovoltaic self-consumption with appliance scheduling in 200 single-family buildings, Appl. Energy 126 (2014) 199-212.

[29] C. Bergaentzlé, C. Clastres, H. Khalfallay, Demand-side management and European environmental and energy goals: An optimal complementary approach, Energy Policy 67 (2014) 858-869.

[30] J.V. Paatero, P.D. Lund, A model for generating household electricity load profiles, Int. J. Energy Res. 30 (2006) 273-290.

[31] ECN, Energie-Nederland, Netbeheer Nederland, Energietrends 2014, 2014 http://energietrends.info/wp-content/uploads/2014/09/EnergieTrends2014. pdf (last accessed 16.12.16).

[32] W. Labeeuw, J. Stragler, G. Deconinck, Potential of active demand reduction with residential wet appliances: A case study for Belgium, IEEE Trans. Smart Grid 6 (2015) 315-323.

[33] A. Abdisalaam, I. Lampropoulos, J. Frunt, G.P.J. Verbong, W.L. Kling, Assessing the economic benefits of flexible residential load participation in the Dutch day-ahead auction and balancing market, in: 9th Int. Conf. Eur. Energy Mark., EEM 12, 2012, pp. 1-8.

[34] A.C. de Keizer, E. Ter Horst, E.C. Molenbroek, W.G.J.H.M. Van Sark, Evaluating 5 -years performance monitoring of $1 \mathrm{MW}$ building integrated PV project in Nieuwland; Amersfoort; the Netherlands, in: G. Willeke, H. Ossenbrink, P. Helm (Eds.), Proc. 22nd Eur. Photovolt. Sol. Energy Conf., WIP-Renewable Energies, Munich, Germany, 2007, pp. 2960-2965.

[35] Pöyry, Assessment of DSR price signals, 2011. http://www.poyry.co.uk/sites/ www.poyry.uk/files/717_DSR_Price_signals_Report_v1_0.pdf (last accessed 16.12.16).

[36] A. Faruqui, D. Harris, R. Hledik, Unlocking the $€ 53$ billion savings from smart meters in the EU: How increasing the adoption of dynamic tariffs could make or break the EU's smart grid investment, Energy Policy 38 (2010) 6222-6231.

[37] G. Barbose, C. Goldman, B. Neenan, A Survey of Utility Experience with Real Time Pricing, 2004. https://eetd.lbl.gov/sites/all/files/publications/reportlbnl-54238.pdf (last accessed 16.12.16).

[38] Tweede kamer der Staten Generaal, Voorzienings- en leveringszekerheid energie, Verslag van een algemeen overleg. (Supply and delivery of energy, Report of a general consultation), 2014.

[39] Ministerie van VROM, Energiegedrag in de Woning, Aanknopingspunten voor de vermindering van het energiegebruik in de woningvoorraad. (Household Energy behavior, Starting points for the reduction of energy use in the housing stock), 2010.

[40] R. Stamminger, G. Broli, C. Pakula, H. Jungbecker, M. Braun, I. Rüdenauer C. Wendker, Synergy potential of smart appliances, report of the SmartA project, 2008. http://www.smart-a.org/D2.3_Synergy_Potential_of_Smart Appliances_4.00.pdf (last accessed 16.12.16).

[41] CBS, Energieverbruik particuliere woningen; woningtype en regio's, (Energy consumption in private households; property type and region), 2016 http://statline.cbs.nl/StatWeb/publication/?DM=SLNL\&PA=81528NED (last accessed 16.12.16).

[42] C. Sandels, J. Widén, L. Nordström, Forecasting household consumer electricity load profiles with a combined physical and behavioral approach, Appl. Energy 131 (2014) 267-278.

[43] NEDU, Verbruiksprofielen, 2016. http://nedu.nl/portfolio/verbruiksprofielen/ (Usage profiles).

[44] Wetenswaardigheden, cijfers en statistieken over de wijk Nieuwland in Amersfoort, (Facts, figures and statistics on the district Nieuwland in Amersfoort), (n.d.). http://www.oozo.nl/cijfers/amersfoort/nieuwland.

[45] M.J. Blom, M. Bleis, C. Leguijt, F.J. Rooijers, R. Van Gerwen, D. Van Hameren, F. Verheij, Maatschappelijke kosten en baten van Intelligente Netten, (Social costs and benefits of Smart Grids), 2012. http://www.ce.nl/publicatie/ maatschappelijke_kosten_en_baten_van_intelligente_netten/1236.

[46] J. Kleissl, Solar Energy Forecasting and Resource Assessment, Academic Press, 2013.

[47] A.G.R. Vaz, B. Elsinga, W.G.J.H.M. Van Sark, M.C. Brito, An artificial neura network to assess the impact of neighbouring photovoltaic systems in power forecasting in Utrecht, the Netherlands, Renew. Energy 85 (2016) 631-641.

[48] B. Elsinga, W.G.J.H.M. Van Sark, Short-term peer-to-peer Solar Forecasting in a Network of Photovoltaic Systems, submitted for publication.

[49] R.H. Inman, H.T.C. Pedro, C.F.M. Coimbra, Solar forecasting methods for renewable energy integration, Prog. Energy Combust. Sci. 39 (2013) 535-576.

[50] A. Arteconi, N.J. Hewitt, F. Polonara, Domestic demand-side management (DSM): Role of heat pumps and thermal energy storage (TES) systems, Appl. Therm. Eng. 51 (2013) 155-165. 